\title{
Downscaling Correction and Hydrological Applicability of the Three Latest High-Resolution Satellite Precipitation Products (GPM, GSMAP, and MSWEP) in the Pingtang Catchment, China
}

\author{
Guikai Sun, ${ }^{1,2,3}$ Yixiong Wei ${ }^{1},{ }^{1,2,3}$ Guoshuai Wang, ${ }^{1,2,3}$ Rui Shi, ${ }^{1,2,3}$ Haojian Chen, ${ }^{1,2,3}$ \\ and Chongxun Mo $\mathbf{M}^{1,2,3}$ \\ ${ }^{1}$ College of Architecture and Civil Engineering, Guangxi University, Nanning 530004, China \\ ${ }^{2}$ Key Laboratory of Disaster Prevention and Structural Safety of Ministry of Education, Nanning 530004, China \\ ${ }^{3}$ Guangxi Provincial Engineering Research Center of Water Security and Intelligent Control for Karst Region, Guangxi University, \\ Nanning, Guangxi 530004, China
}

Correspondence should be addressed to Yixiong Wei; 1910303008@st.gxu.edu.cn

Received 3 September 2021; Accepted 25 November 2021; Published 28 January 2022

Academic Editor: Tomeu Rigo

Copyright (C) 2022 Guikai Sun et al. This is an open access article distributed under the Creative Commons Attribution License, which permits unrestricted use, distribution, and reproduction in any medium, provided the original work is properly cited.

The emergence of various high-resolution satellite precipitation products (SPPs) solves the problem of precipitation data sources for areas with a lack of precipitation data and is recognized as a reliable supplement to rain gauge observations in hydrometeorological applications. However, there still exists a shortcoming of coarse spatial resolution when applying these products to small and microscale river basins. In this study, a typical karst watershed in Southwest China - the Pingtang River Basin (PTRB) was selected, and based on the relationship between precipitation and normalized difference vegetation index (NDVI), aspect, slope, and elevation, we used the geographically weighted regression (GWR) to downscale three SPPs, namely, global precipitation measurement (GPM), global satellite mapping of precipitation (GSMAP), and multisource weighted-ensemble precipitation (MSWEP), to $1 \mathrm{~km} \times 1 \mathrm{~km}$, respectively. Combined with rain gauge stations, the geographical differential analysis (GDA) was used to carry out error corrections to obtain three downscaling correction satellite precipitation products (DC-SPPs) with a $1 \mathrm{~km}$ spatial resolution, including DC-GPM, DC -GSMAP, and DC-MSWEP. Several statistical indices were used to perform error evaluation and precipitation capture ability analysis on SPPs and DC-SPPs, and the Grid-Xin'anjiang (the Grid-XAJ) model was used to compare their hydrological utility. The results show the following: (1) The downscaling correction method is effective. GWR can effectively improve the spatial resolution of SPPs, while GDA can reduce errors and further improve the accuracy of precipitation estimation. In addition, (2) the precipitation event characterization capabilities of GPM and GSMAP have been improved after downscaling correction, while the ability to capture precipitation events before and after the MSWEP correction is poor, showing a high hit rate and a high false alarm rate, which is unreliable to monitor precipitation events in the PTRB. Finally, (3) compared with SPPs, the hydrological performances of the three kinds of DC-SPPs have been significantly improved, and the NSE are all above 0.75 with low error. In general, the overall performance of DC-GSMAP is satisfactory. The accuracy of different SPPs after downscaling correction is different, but the applicability has been improved to different degrees.

\section{Introduction}

The advancement of science and technology has caused great changes in the approach to how precipitation is measured [1-3]. Because of the large-scale, wide-coverage, and strong spatial representation of satellite remote sensing measurements, this process has become one of the important tools for estimating global and regional precipitation [4]. A variety of derived satellite precipitation products (SPPs) with a high temporal and spatial resolution has been released [5], and these can provide hydrometeorological researchers with potential alternative sources for precipitation data, which has great application prospects, especially in areas with sparse rain gauges or lacking precipitation data. Currently, the most commonly used and easily accessible SPPs include the tropical rainfall measuring mission (TRMM) [6], climate 
prediction center's morphing technique (CMORPH) [7], precipitation estimation from remotely sensed information using artificial neural network (PRESIANN) [8, 9], global precipitation measurement (GPM) [10], global satellite mapping of precipitation (GSMAP) [11], and multisource weighted-ensemble precipitation (MSWEP) [12].

Precipitation is one of the important key inputs of hydrological modeling [13]. Hydrological models driven only by point precipitation data measured by sparse rain gauge stations can no longer meet the accuracy requirements of basin hydrological simulations. However, the emergence of SPPs overcomes the limitation of insufficient regional representativeness of precipitation data measured by rain gauge stations and significantly enhances the precipitation measurements [14]. Compared with rain gauge observations, the satellites use indirect methods to estimate precipitation, thereby making the quality of SPPs vulnerable to the uncertainty of the inversion algorithm and the nonuniformity of the sensor's field of view sampling frequency, as well as geographic location, topography, regional hydrometeorological characteristics, and influencing of factors such as complexity [15]. In recent years, many studies have conducted multiple comprehensive evaluations on the performance of different SPPs in diverse regions [16-21] and have found that the accuracy performance of SPPs in different regions and climatic conditions is not the same and that there are non-negligible deviations. Therefore, SPPs are actually used in related hydrometeorological fields, and there is a need to carry out accuracy assessment and bias correction before quantifying the error of SPPs and the ability to characterize precipitation events [22]. However, most of the previous studies were conducted on global and regional large-scale assessments, and there is still a lack of applied research on small-scale areas [23]. Compared with largescale catchments, small catchments are seen as ideal objects, and they are usually used to study small and microscale hydrology, water resources, and water environments. More importantly, with the continuous improvement of satellite remote sensing technology and equipment and precipitation retrieval algorithms, the quality of SPPs improved continuously. Therefore, the previous research and evaluation results also need to be further improved [24].

Currently, the spatial and temporal resolution of newly released SPPs is up to 0.1 degrees and 0.5 hours. When applied to small- and microscales, there are still problems of insufficient resolution and error uncertainty. Therefore, the downscaling correction of SPPs is necessary [25], i.e., it can obtain precipitation data with higher spatial resolution and better quality. Spatial downscaling is based on the assumption that there is a significant relationship between precipitation and environmental factors [26]. By establishing a statistical model of precipitation and these factors, it is a feasible method to downscaling precipitation, which is called a statistical downscaling algorithm [27]. Previous studies have selected one or more environmental factors to spatially downscale satellite precipitation products. Immerzeel et al. [28] used a geographic weighted regression model (GWR) to spatially downscale TRMM by environmental factors (NDVI). The downscaling procedure resulted in significant improvements in correlation, bias, and root mean square error for average annual precipitation over the whole period. Cheng et al. [29] used a downscaling integration framework and two environmental variables (NDVI and DEM) and downscaled the spatial resolution of IMERG daily precipitation products in eastern and central China from $0.1^{\circ}$ to $1 \mathrm{~km}$, which is more accurate than the original IMERG data after downscaling. Chesheng et al. [30] found that the precipitation regression effect of GWR based on NDVI and DEM is significantly better than that of MLR in the Hengduan Mountains of China, and the contribution of DEM to precipitation is greater than that of NDVI. Patricia et al. [31] established a GWR model using four environmental factors (EVI, elevation, slope, and aspect) to downscale four different SPPs (CMORPH, MSWEP, PERSIANN, and TRMM) in the Magdalena river basin in Colombia. The accuracy of the four different SPPs after downscaling has been improved to varying degrees. Overall, these precipitation-influencing factors were varied by hydroclimate properties. For instance, vegetation cover or distribution is more significant in a temperate climate region. Topography is more relevant to mountainous watersheds [32]. Humidity and distance to the sea are more influential environmental variables in humid tropics [33]. In the past, most researchers focused on larger regional scales and selected fewer environmental factors in most studies [34-36]. In this study, a typical karst watershed was selected in the mountainous area of southwest China-PTRB. According to the hydrological and climatic conditions of the watershed, four environmental factors (NDVI, DEM, slope, and aspect) were selected to downscale the three SPPs.

The GWR did not supplement accurate precipitation observation data in the process of downscaling. The effect of improving the accuracy is not obvious, and it cannot fully reflect the small-scale and microscale precipitation changes in the basin. Therefore, it is extremely critical to use precipitation from rain gauge stations to correct the deviation of the precipitation products obtained by the GWR model [37]. Some pieces of research have shown that geographic difference analysis (GDA) has greater advantages in applying precipitation correction grid precipitation products at rain gauge stations $[38,39]$. It can correct the deviation of the satellite grid precipitation data based on the precipitation data of the rain gauge stations and achieve better correction results [27]. This study explores the simultaneous application of GWR and GDA to the postprocessing of satellite precipitation products, aiming to obtain higher resolution and bias-corrected precipitation products.

The hydrological applicability of SPPs and DC-SPPs has always attracted the attention of an increasing number of hydrological researchers [40-42]. Compared with the previous study area, the catchment area above the Pingtang Hydrological Station is a typical karst basin. The topography and landform are more complex, the vegetation is relatively simple, and the runoff response process is extremely complex, which makes the hydrology of the basin circulation different from that of other watersheds [43]. It is crucial to combine the temporal and spatial representation of satellite precipitation products with the accuracy of 
precipitation data from rain gauge stations to obtain more refined precipitation products and explore the applicability in hydrological simulations, which can be used to better understand them as supplementary data to the study karst basins of hydrological utility [39]. However, to the best of our knowledge, there are few or no studies on the accuracy performance and hydrological utility comparison of multiple SPPs in karst areas. It is worthy of attention in the application research of SPPs.

In this study, the GWR model is established by introducing several precipitation-influencing factors (NDVI, slope, aspect, and elevation), and the three SPPs (GPM, GSMAP, and MSWEP) are downscaled to obtain a $1 \mathrm{~km}$ spatial resolution. Next, GDA is used to correct the three downscaled precipitation products to obtain three types of DC-SPPs (DCGPM, -GSMAP, and DC-MSWEP). Finally, the accuracy of all SPPs and DC-SPPs is evaluated in many ways, and they are used as inputs to drive the Grid -XAJ model that was calibrated by rain gauge stations to compare their performance in the runoff simulation during the verification period. On the one hand, the research results facilitate the selection of appropriate SPPs in the basin as a supplement to the observation of rain gauges and better respond to extreme precipitation event monitoring, flood disaster assessment, and water resource scheduling management. In addition, it can also select suitable SPPs for river basins in karst areas with similar hydrological and climatic conditions. Precipitation products provide a reference. On the other hand, for the developers of satellite precipitation product algorithms to understand the advantages and disadvantages of precipitation estimation in different geographic locations and different precipitation conditions, they can improve the existing precipitation algorithms and bias correction procedures.

\section{Study Area and Data Sets}

2.1. Study Area. The PTRB is a catchment area above the Pingtang Hydrological Station. The catchment area of the entire catchment is approximately $1392 \mathrm{~km}^{2}$ and is located in southwest China. It is a typical karst basin. There are many karst features, such as caves, sinkholes, and skylights in the basin. Undercurrents and alternately exist, especially in the northeastern part of the basin. They are mostly underground undercurrents. The basin is located in the subtropical monsoon climate zone. The annual average precipitation in the basin is $1560 \mathrm{~mm}$, and the annual average temperature is $22.1^{\circ} \mathrm{C}$. The rainy season is rich in precipitation. The inflow of the Pingtang Hydrological Station during the flood season accounts for approximately $80 \%$ of the annual inflow. The surface vegetation coverage of the basin is relatively simple, the soil water retention capacity is extremely poor, the confluence process is extremely complicated, and flood disasters occur frequently (Figure 1 ).

\subsection{Dataset Description}

2.2.1. Gauge Precipitation Data. This study uses the daily rain gauge data of 8 rain gauges in the PTRB from 2002 to 2019. The discharge data of the Pingtang hydrological station are all provided by the Chengbi River Reservoir Administration. The quality of the discharge data was controlled and can be used as true values to compare and evaluate SPPs and DC-SPPs. The GPS coordinates and elevations of the 8 stations are shown in Table 1.

2.2.2. Satellite Precipitation Products. All SPPs used in this study have high-precision spatial $\left(0.1^{\circ}\right.$ latitude/longitude) and time (daily) resolution. In the statistical evaluation process, the SPP pixels that contain at least one rain gauge station are first extracted. Then, each pixel is extracted. The data from the ground stations in the station are averaged to obtain an in situ match for a more accurate evaluation of satellite precipitation products. The sources and brief introductions of the three SPPs are as follows:

(1) GPM IMERG is a three-level precipitation product (hereinafter referred to as GPM) derived from the global satellite precipitation map (GPM) satellite algorithm launched on February 28, 2014. The algorithm is combined with precipitation meter analysis, microwave calibration infrared satellite estimation, and other precipitation estimates [44]. Using the global precipitation climatology center (GPCC) ground, the monthly precipitation data mutual calibration and interpolation of multisatellite microwave precipitation estimation methods have been updated to the V6B version [45] to provide a smaller spatial resolution $\left(0.1^{\circ}\right)$, a greater quasi-global coverage $\left(60^{\circ} \mathrm{S}-60^{\circ} \mathrm{N}\right)$, and a near-real-time (30 minutes) of the latest generation of satellite precipitation products. The GPM product used in this article is measured and adjusted by monitoring the monthly gauge data from the global precipitation climatology center (GPCC), and the delayed release date is two months. The GPM is derived from the precipitation measurement mission website (https://gpm.nasa.gov/dataaccess/downloads/gpm).

(2) The satellite precipitation products provided by the GSMAP project combine the infrared data and passive microwave data using the satellite data to provide precipitation at $60^{\circ} \mathrm{S}-60^{\circ} \mathrm{N}$ in the latitude zone and global precipitation with high-quality spatiotemporal resolution at a spatial resolution of $0.1^{\circ}$, which has been updated to version V7. The GSMAP-gauge (hereinafter referred to as GSMAP) used in this article is a product that has been calibrated with a meter. Its delay time is 3 days. It uses the instrument-based global daily precipitation analysis of the National Oceanic and Atmospheric Administration/Climate Prediction Center (CPC). Adjust the generation of microwave-infrared reanalysis products (GSMAP-MVK) [11], and the GSMAP was downloaded from the GSMAP official website (https://sharaku.eorc.jaxa.jp/GSMaP).

(3) MSWEP is a complete global precipitation dataset that is optimized and merged by a series of 


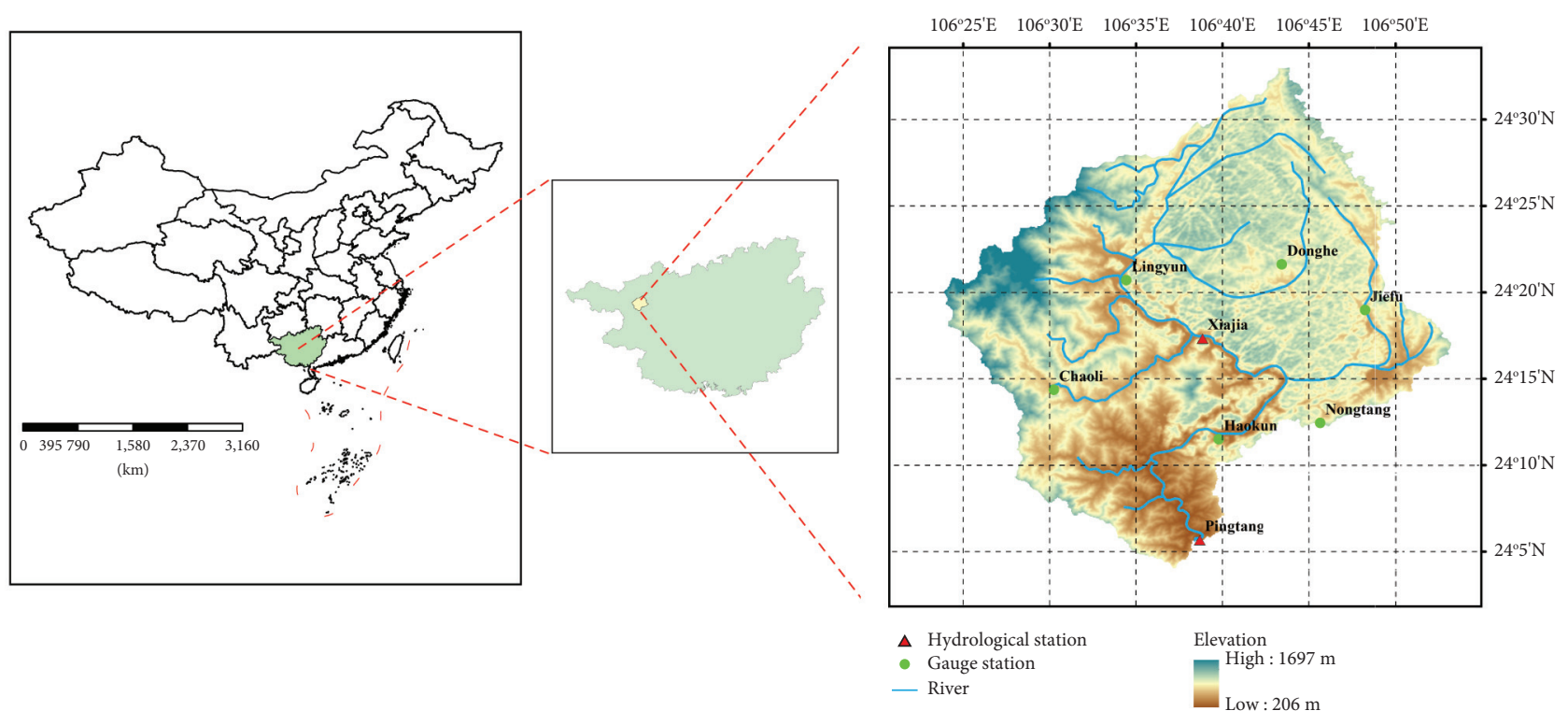

(a)

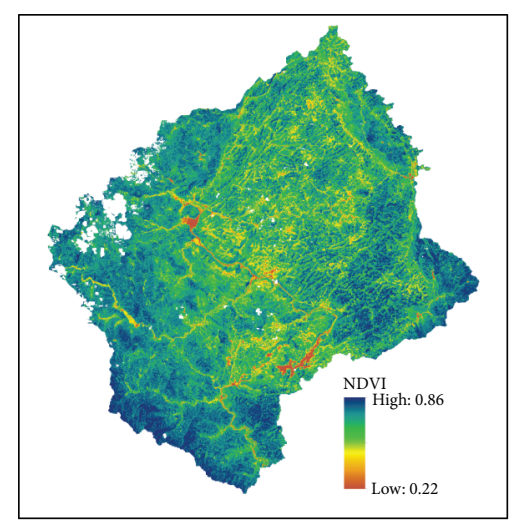

(b)

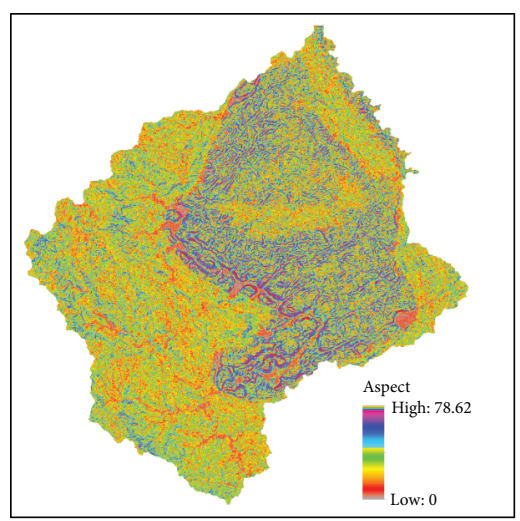

(c)

Figure 1: Continued. 


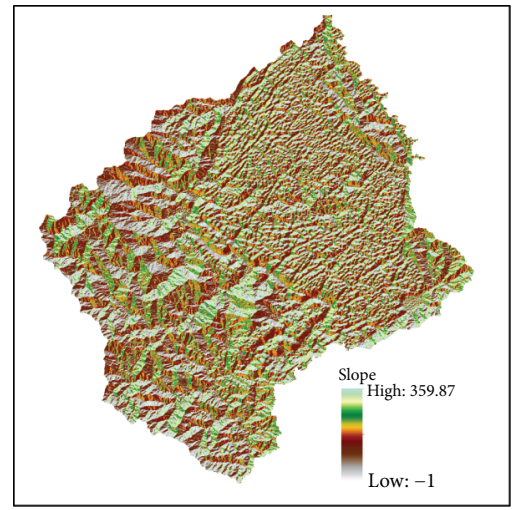

(d)

FIgUre 1: The spatial distribution of rain gauge stations in the Pingtang River Basin. (b) Mean annual NDVI, (c) aspect, and (d) slope.

TABLE 1: GPS coordinates and elevation of eight gauge stations.

\begin{tabular}{|c|c|c|c|c|}
\hline Station number & Name & Longitude (E) & Latitude $(\mathrm{N})$ & Elevation $(\mathrm{m})$ \\
\hline 1 & Lingyun (LY) & $106^{\circ} 34^{\prime} 26^{\prime \prime}$ & $24^{\circ} 20^{\prime} 42^{\prime \prime}$ & 444 \\
\hline 2 & Donghe (DH) & $106^{\circ} 43^{\prime} 26^{\prime \prime}$ & $24^{\circ} 21^{\prime} 37^{\prime \prime}$ & 897 \\
\hline 3 & Jiefu (JF) & $106^{\circ} 48^{\prime} 15^{\prime \prime}$ & $24^{\circ} 18^{\prime} 58^{\prime \prime}$ & 425 \\
\hline 4 & Chaoli (CL) & $106^{\circ} 30^{\prime} 15^{\prime \prime}$ & $24^{\circ} 14^{\prime} 22^{\prime \prime}$ & 625 \\
\hline 5 & Xiajia (XJ) & $106^{\circ} 38^{\prime} 51^{\prime \prime}$ & $24^{\circ} 17^{\prime} 19^{\prime \prime}$ & 385 \\
\hline 6 & Haokun (HK) & $106^{\circ} 39^{\prime} 47^{\prime \prime}$ & $24^{\circ} 11^{\prime} 30^{\prime \prime}$ & 532 \\
\hline 7 & Nongtang (NT) & $106^{\circ} 45^{\prime} 39^{\prime \prime}$ & $24^{\circ} 12^{\prime} 27^{\prime \prime}$ & 386 \\
\hline 8 & Pingtang (PT) & $106^{\circ} 38^{\prime} 41^{\prime \prime}$ & $24^{\circ} 05^{\prime} 39^{\prime \prime}$ & 213 \\
\hline
\end{tabular}

measuring instruments, satellites, and reanalysis estimates [12]. It has a time resolution of 3 hours and a spatial resolution of $0.1^{\circ}$. Having been updated to the V2.8 version, the time variability of MSWEP is determined by the anomalous weighted average of 7 datasets, including three kinds of satellite remote sensing precipitation products (CMORPH, GSMAP-MVK, and TMPA 3B42RT) and two kinds of atmospheric model reanalysis (ERA-Interim and JRA-55) [46]. The MSWEP used in this article was downloaded from (http://www. gloh2o.org/).

The time range of the three SPPs is from January 1, 2014, to December 31, 2019. The original recording time of the three SPPs is the universal time, and UTC $+8 \mathrm{~h}$ is used to convert the universal time to Beijing time to match the precipitation data of the rainfall station.

2.2.3. Data for the Grid-XAJ Model and GWR Model. The normalized vegetation index NDVI used in this study is derived from the data of the MOD13A3 version published on the official website (https://search.earthdata.nasa.gov/) of the Land Product Distribution Center (LPDAAC) jointly established by the United States Geological Survey (USGS) and the National Aeronautics Administration (NASA) [47]. The $90 \mathrm{~m}$ resolution digital elevation model (DEM) is provided by the Computer Network Information Center of the Chinese Academy of Sciences. The elevation, slope, and aspect required for the model are all calculated from DEM.

\section{Methodology}

3.1. Statistical Evaluation Indices. Table 2 shows the calculation formulas of seven metrics and their perfect values. Firstly, four error evaluation metrics are used to quantify the error of SPPs and SPPs. Four error evaluation metrics are used to quantify the error of SPPs and SPPs. The correlation coefficient (CC) reflects the degree of consistency between the precipitation products and precipitation at rainfall stations. The root mean square error (RMSE) mainly represents the average range of error between the two sets of data. The average absolute error (MAE) can more accurately measure the error between the two sets of data, and the relative deviation $(\mathrm{RB})$ indicates the degree of deviation of the satellite precipitation product relative to the precipitation at the rain gauge station [22]. In addition, three statistical metrics of probability, namely the probability of detection (POD), false alarm rate (FAR), and equitable threat score (ETS), are also used to characterize the ability of satellite precipitation products to capture precipitation events [30]. POD represents an accurate representation of satellite precipitation products. The percentage of precipitation events was accurately detected. FAR represents the proportion of observed precipitation events that did not occur. ETS comprehensively evaluates the ability of precipitation products to estimate the occurrence of precipitation events. NSE represents the overall efficiency of the hydrological model that is more sensitive to the high values of runoff, while lgNSE is more sensitive to the low values of runoff. Both can quantify the hydrological performance of all precipitation products [42]. 
TABLE 2: List of statistical metrics used in the statistical and hydrologic evaluations.

\begin{tabular}{|c|c|c|}
\hline Evaluation indices & Formula & Perfect value \\
\hline Correlation coefficient (CC) & $\mathrm{CC}=\sum_{i=1}^{n}\left(O_{i}-\bar{O}\right)\left(S_{i}-\bar{S}\right) / \sqrt{\sum_{i=1}^{n}\left(O_{i}-\bar{O}\right)^{2} \times \sum_{i=1}^{n}\left(S_{i}-\bar{S}\right)^{2}}$ & 1 \\
\hline Mean absolute error (MAE) & MAE $=(1 / n) \sum_{i=1}^{n}\left|O_{i}-S_{i}\right|$ & 0 \\
\hline Root mean squared error (RMSE) & $\operatorname{RMSE}=\sqrt{(1 / n) \sum_{i=1}^{n}\left(O_{i}-S_{i}\right)^{2}}$ & 0 \\
\hline Relative bias (RB) & $\mathrm{RB}=\left(\sum_{i=1}^{n}\left(S_{i}-O_{i}\right) / \sum_{i=1}^{n} O_{i}\right) \times 100 \% /\left(\sum_{i=1}^{n}\left(Q_{S i}-Q_{O}\right) / \sum_{i=1}^{n} Q_{O i}\right) \times 100 \%$ & 0 \\
\hline Probability of detection (POD) & POD $=A / A+C$ & 1 \\
\hline False alarm ratio (FAR) & $\mathrm{FAR}=B / A+B$ & 0 \\
\hline Equitable threat score (ETS) & $\mathrm{ETS}=(A-R / A+B+C-R), R=(A+C) \cdot(A+B) / A+B+C+D$ & 1 \\
\hline $\begin{array}{l}\text { Nash-Sutcliffe model efficiency coefficient } \\
\text { (NSE) }\end{array}$ & $\mathrm{NSE}=1-\left(\sum_{i=1}^{n}\left(Q_{S i}-Q_{O i}\right)^{2} / \sum_{i=1}^{n}\left(Q_{O i}-\overline{Q_{O i}}\right)^{2}\right)$ & 1 \\
\hline $\begin{array}{l}\text { Logarithmic Nash-Sutcliffe model efficiency } \\
\text { coefficient (lgNSE) }\end{array}$ & $\operatorname{lgNSE}=1-\left(\sum_{i=1}^{n}\left[\lg \left(Q_{S i}\right)-\lg \left(Q_{O i}\right)\right]^{2} / \sum_{i=1}^{n}\left[\lg \left(Q_{O i}\right)-\overline{\lg \left(Q_{O i}\right)}\right]^{2}\right)$ & 1 \\
\hline
\end{tabular}

Note. $n$ is the number of samples, $i$ represents the $i^{\text {th }}$ sample data, $S$ represents that the precipitation is estimated from satellites or corrected satellite precipitation products, and $O$ represents the precipitation from rain gauge stations. $A$ represents the number of precipitation events simultaneously observed by the satellite and the rainfall station, $B$ represents the number of precipitation events observed by the satellite but not observed by the rainfall station, $C$ represents the number of precipitation events not observed by the satellite but observed by the rainfall station, and $D$ is the number of precipitation events that neither of them captured. $Q_{S}$ is the simulated runoff of the hydrological model, and $Q_{O}$ is the flow measured by the hydrological station.

3.2. Downscaling Correction. Figure 2 shows the flow chart of the reduction rule used in this study. The relationship between various variables in space usually has spatial heterogeneity. If the traditional linear regression model (GLM) is used to analyze the relationship between variables, it often has a large deviation from the actual situation, and the interpretation of the characteristics of the more important local variables is insufficient. GLM assumes that the relationship between the variables is homogeneous. The GWR model is a local regression model that considers spatial location and solves this problem. The basic idea is that the relationship between the variables changes with a change in spatial location. By estimating the relative variables and sums of each given location in the study area, the optimal parameters of the explanatory variables are used to establish a regression model [48]. Based on this characteristic, the GWR model has an ideal effect when studying precipitation heterogeneity. Therefore, this study selects the GWR model to downscale SPPs to improve the spatial resolution of SPPs. The GDA is very outstanding in combining the advantages of satellite precipitation products and rain gauge precipitation and improving the deviation between them. GDA has the advantages of a good correction effect and simple calculation [39]. Thus, GDA is used to modify the precipitation products obtained by the GWR model downscaling and to obtain the final DC-SPPs.

3.3. Grid-XAJ Model. In this study, the Grid-XAJ model was used to evaluate the hydrological simulation characteristics of SPPs and DC-SPPs. As SPPs are the grid points of precipitation data, they can be directly input into the Grid-XAJ model and be used to evaluate the performance of satellite precipitation products. Therefore, it results in the advantages of the better spatial distribution of grid-point precipitation data. The GridXAJ model is a conceptual and distributed hydrological model that is well applied in the semihumid and humid regions of China [49]. In recent years, with the combination of the traditional Xin'anjiang model and DEM, GIS, and other technologies, building a Grid-Xin'anjiang distributed model based on a DEM grid has become the main direction of the current Xin'anjiang model development [50]. The Grid-XAJ model is based on the DEM and remote sensing geomorphology data, and the river basin is discretized into uniform grid units. Based on the model structure of the traditional three-water source Xin'anjiang model [51], each unit grid is used as an independent runoff calculation. The distributed hydrological model of the unit can better reflect the unevenness of the spatial distribution of precipitation and the underlying surface and make the hydrological simulation closer to the real hydrological process. The Grid-XAJ model uses the traditional three-source Xin'anjiang model after the distributed processing of the watershed. The model structure consists of four modules, namely evapotranspiration, runoff, water distribution and confluence, and 16 model parameters. The model structure diagram is shown in Figure 3. The evapotranspiration module includes 5 parameters, namely WUM, WLM, WDM, KC, and C. The runoff module includes 2 parameters, namely $\mathrm{B}$ and IMP. The water distribution module includes 4 parameters, namely SM, EX, KG, and $\mathrm{KI}$, and the convergence module includes 5 parameters, namely CS, CSS, CG, KE, and XE [29, 52]. This study also adjusted the structure of the runoff generation module of the traditional Grid-XAJ model to reduce the uncertainty of the model itself, i.e., the rainfall distribution coefficient is introduced into the runoff generation module of the model, and precipitation can directly enter the free storage reservoir. This parameter represents the degree of development of karst landforms in the basin. The higher the degree of development, the higher the proportion of directly replenishing groundwater. All of the perfect values of the calibrated parameters about the Grid-XAJ model can be seen in Table 3 .

\section{Results}

\subsection{Performance of SPPs and DC-SPPs at Multiple Temporal Scales}

4.1.1. Daily Scale. Figure 4 shows the density-dispersion plot and the error evaluation indicators of all precipitation 


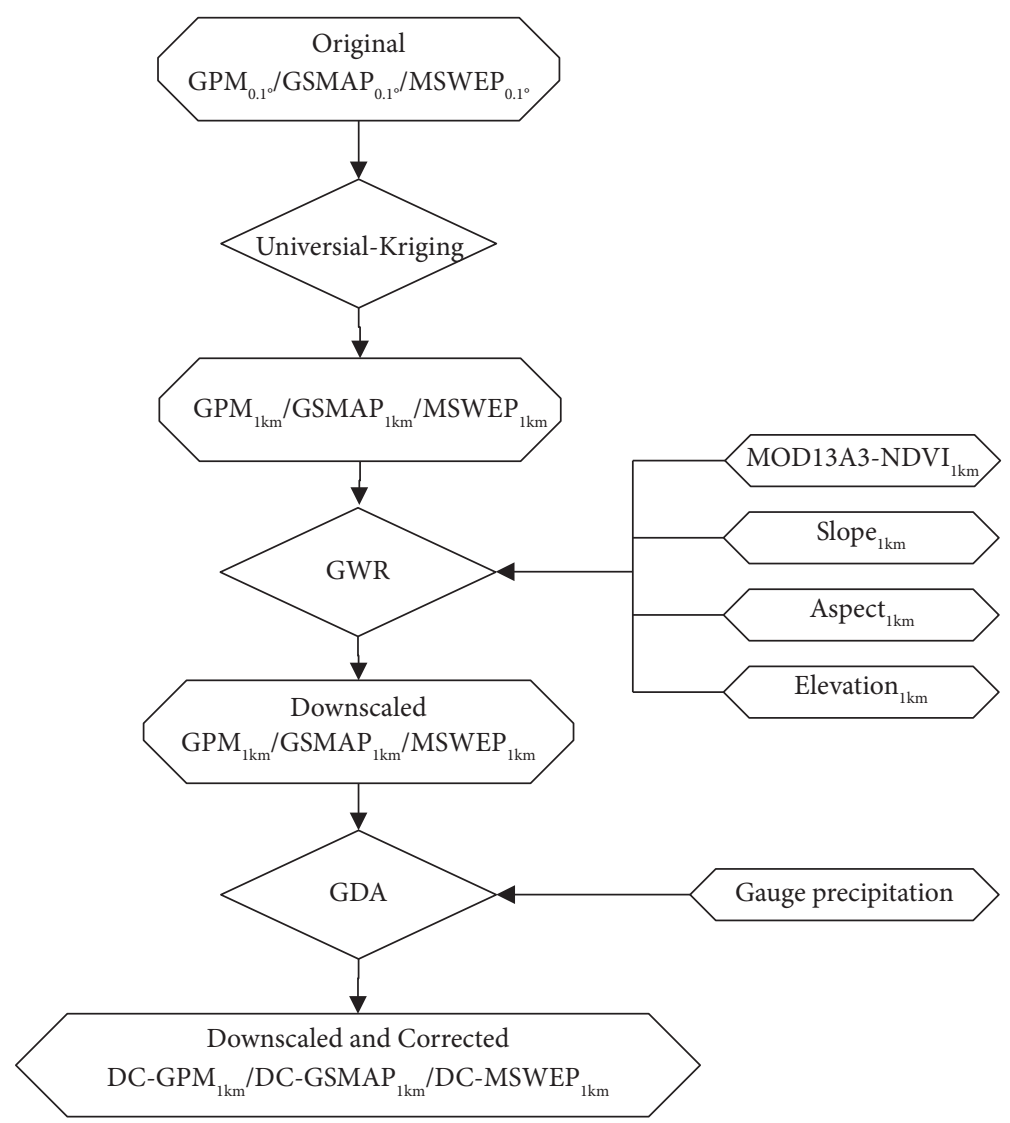

Figure 2: The flow chart of the downscaling correction method in this study.

products and daily scale rainfall station observations. The CCs of the three SPPs are all higher than 0.65, the GPM has the best consistency with rainfall at the rainfall station (CC is 0.69 ), and the RB ranges from $-8.29 \%$ to $-12.09 \%$, all of which show an underestimation of the daily precipitation in the basin. The maximum MAE of MSWEP is $4.06 \mathrm{~mm}$, and the maximum RMSE of GSMAP is $10.51 \mathrm{~mm}$. The error performance of GSMAP is slightly better than that of GPM and MSWEP. The three kinds of DC-SPPS are better than the corresponding SPPs in terms of consistency and reduction of various errors. DC-MSWEP has the highest CC (0.95) on a daily scale and is closely aligned with the observation data of the surface rainfall stations. RB and RMSE are the smallest (e.g., $-4.14 \%$ and $5.14 \mathrm{~mm}$ ), while MAE is the largest $(2.03 \mathrm{~mm})$. Research shows that MAE can better reflect the error level of SPPs. The RBs of the three types of DC-SPPS are all less than $0(-7.12 \%,-4.72 \%$, and $-4.14 \%$, respectively), indicating that the precipitation products still underestimate the daily precipitation in the basin after downscaling correction.

4.1.2. Monthly Scale. Figure 5 shows the time trend of the four error statistical metrics from January 2014 to December 2019. All SPPs and DC-SPPs can effectively reflect the time trend of error evaluation indicators. The precipitation in the PTRB is mainly concentrated from June to August, which corresponds to summer in China. These metrics usually change with the seasons of high and low rainfall in the basin. The CC values of all SPPs and DC-SPPs are lower in the dry season (October to April) and higher in the wet season (May to September), while the RMSE and MAE have opposite changes. The variation trends of the error statistical indicators of the three SPPs on a monthly scale are relatively similar. The error statistical indicators of GPM and GSMAP have relatively stable changes, while MSWEP has large fluctuations. It indicates that the precipitation retrieval algorithm and the original correction of GPM and GSMAP help improve the accuracy of the entire time series. The three types of DC-SPPS and rainfall stations have good consistency in the change in precipitation over time. Among these statistics, the RMSE and RB fluctuations of DC-MSWEP are relatively large. The error of all precipitation products in the wet season is greater than that in the dry season. It is related to the precipitation in the PTRB being mainly concentrated in the wet season. Specifically, the improvement of precipitation error accuracy by downscaling fusion mainly occurs in the wet season, while the improvement in the dry season is not very obvious. Subsequently, it is related to the misreporting of microprecipitation events in the basin during the dry season.

Figure 6 shows the trend of all SPPs and DC-SPPs' ability to capture precipitation events in the watershed with monthly scale time changes. The time scale changes of POD, FAR, and ETS are similar to the time scale changes of precipitation error, and the same detection ability in the 


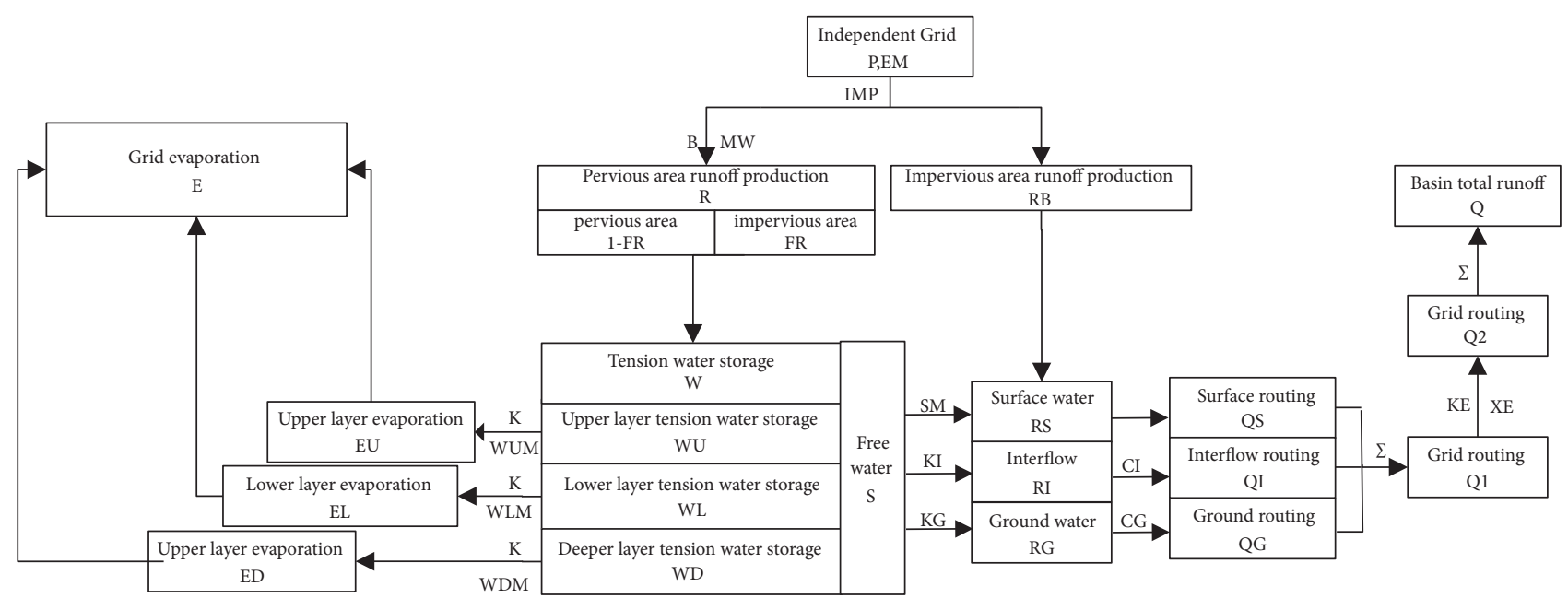

FIgURE 3: Structure of the K-XAJ model.

TABLE 3: Calibrated parameters of the Grid-XAJ model.

\begin{tabular}{|c|c|c|c|c|}
\hline Module & Parameter & Physical meaning & Perfect value & Unit \\
\hline \multirow{5}{*}{ Evapotranspiration } & WUM & Areal mean water capacity of the upper layer & 11.10 & $\mathrm{~mm}$ \\
\hline & WLM & Areal mean tension water capacity of the lower layer & 97.6 & $\mathrm{~mm}$ \\
\hline & WDM & Areal mean tension water capacity of deeper soil layer & 38.9 & $\mathrm{~mm}$ \\
\hline & KC & Ratio of potential evapotranspiration to pan evaporation & 0.93 & - \\
\hline & $\mathrm{C}$ & Evapotranspiration coefficient of deep layer & 0.27 & - \\
\hline \multirow{3}{*}{ Runoff production } & $\varphi$ & Precipitation distribution coefficient & 0.23 & - \\
\hline & $\mathrm{B}$ & Exponential of the distribution to tension water capacity & 0.37 & - \\
\hline & IMP & Ratio of impervious area to the total area of the basin & 0.04 & - \\
\hline \multirow{4}{*}{ Runoff separation } & SM & Areal mean free water storage capacity & 89 & $\mathrm{~mm}$ \\
\hline & EX & Exponential of the distribution of free water storage capacity & 1.22 & - \\
\hline & KG & Outflow coefficient of free water storage to the groundwater & 0.23 & - \\
\hline & KI & Outflow coefficient of free water storage to the interflow & 0.38 & - \\
\hline \multirow{5}{*}{ Runoff routing } & CS & Recession constants of the surface water storage & 0.55 & - \\
\hline & $\mathrm{CI}$ & Recession constants of the interflow storage & 0.87 & - \\
\hline & CG & Recession constant of the lower groundwater storage & 0.98 & - \\
\hline & KE & Outflow coefficient of free water storage to the groundwater & 29.22 & $\mathrm{~h}$ \\
\hline & $\mathrm{XE}$ & Parameter of the muskingum method & 0.12 & - \\
\hline
\end{tabular}

wet season is better than that in the dry season. Compared with SPPs, the GSMAP's POD and ETS are better than GPM. FAR is lower than GPM, indicating that the performance improvement of GPM is not as obvious as that of GSMAP (it is similar to that person's research). On the one hand, this may be because the rainfall station data introduced in the calibration algorithm of GSMAP are CPC daily data. The ground station data introduced in GPM result with the difference caused from GPCC monthly data because the GPCC monthly data may have limited ability to correct precipitation at time steps shorter than one month. The POD of MSWEP was basically above 0.90 during the entire study sequence, however, the FAR of both was significantly higher than that of other precipitation products, showing a high POD and a high FAR. The accuracy of detecting precipitation events was high, and there were also high errors. It is possible to report precipitation events. The ETS error curve is the lowest of the three SPPs, where the precipitation monitoring ability is the worst, and the representation of precipitation events is the least reliable. The reason may be that the inversion algorithm of MSWEP introduces near-real-time SPPs. It is caused by adding less rainfall station data. Compared with the corresponding satellite precipitation products, POD and ETS of the three types of DC-SPPs have improved to varying degrees. Compared with DC-MSWEP, DC-GPM and DC-GSMAP have improved the ability to monitor precipitation events clearly, but the FARs of the three are reduced. It is not obvious, especially MSWEP, which indicates that GWR and GDA used in the article are insufficient in reducing the false alarm rate of SPPs. It also indicates that the introduction of fine rainfall station data for processing before the release of SPPs can improve the capture of precipitation events in SPPs later. Thus, the ability is more important.

4.1.3. Seasonal Scale. This study also evaluated the seasonal precipitation of all SPPs and SPPSs. Table 4 lists CC, MAE, 


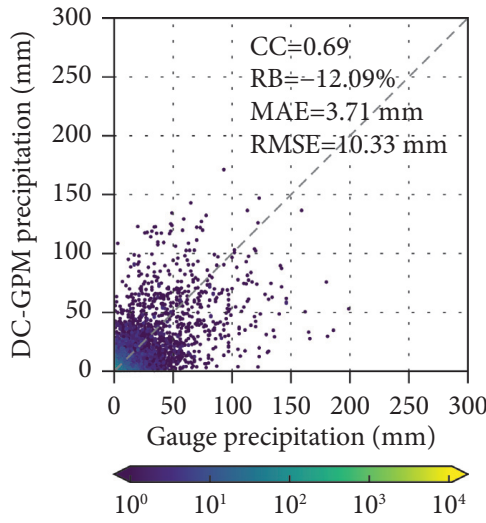

(a)

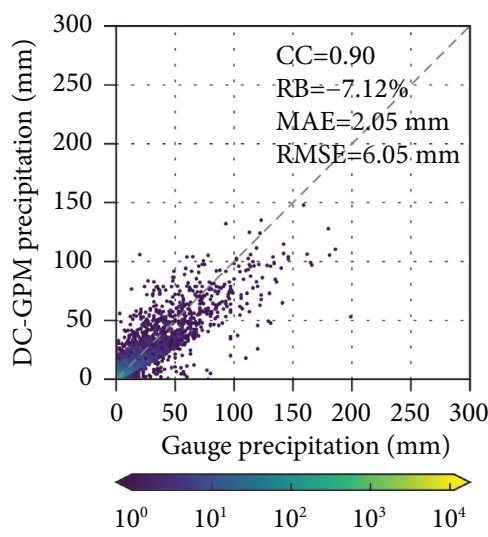

(d)

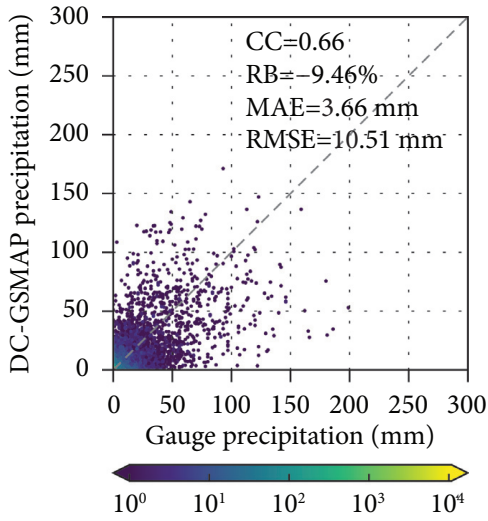

(b)

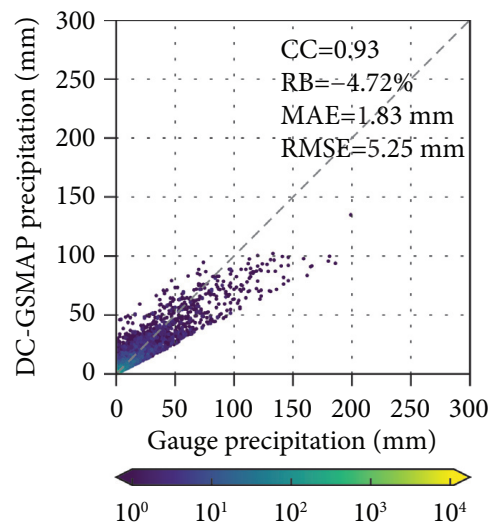

(e)

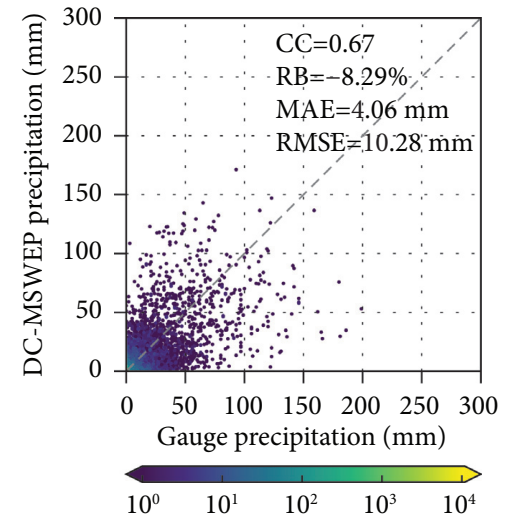

(c)

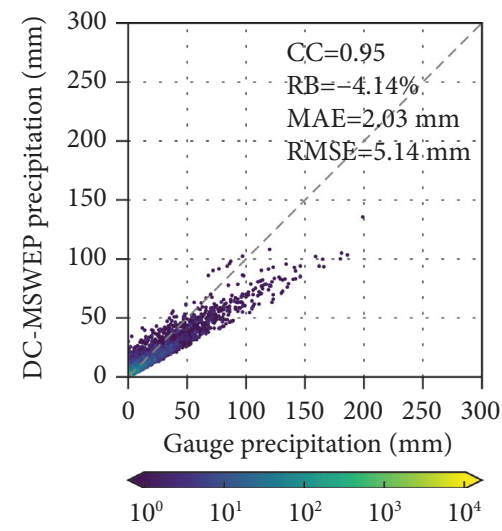

(f)

FIGURE 4: Density color scatter plots of SPPs and DC-SPPs and daily scale rain gauge observations. (a) GPM, (b) GSMAP, (c) MSWEP, (d) DC-GPM, (e) DC-GSMAP, and (f) DC-MSWEP.

RMSE, and RB for all SPPs and SPPSs on a seasonal scale. The CC of GPM, GSMAP, and MSWEP reached 0.6 or more in all seasons, and they all correlated well with the rain gauge observations. In general, the three SPPs can achieve good results, of which CC is between 0.60 and $0.88 \mathrm{~mm}, \mathrm{MAE}$ is between 0.5 and $3 \mathrm{~mm}$, RMSE is between 1.94 and $16.50 \mathrm{~mm}$, and the absolute value of RB is $50 \%$. All three results underestimate the precipitation in spring, summer, and autumn, ranging from $-0.8 \%$ to $-17.64 \%$. GPM underestimates summer precipitation the most seriously, with $\mathrm{RB}$ reaching $-17.64 \%$. The three SPPs underestimate winter precipitation, with an overestimation ranging from $2.74 \%$ to $37.87 \%$. Among them, MSWEP has the most severe overestimation, with $\mathrm{RB}$ reaching $37.87 \%$. Compared with SPPs, the performance of DC-SPPs has improved significantly, and all indicators have been improved to different degrees. The CCs are all higher than 0.9 (except for DC-GPM, which is 0.88 in spring), MAE is between 0.29 and 4.22, and RMSE is between 0.97 and 9.25. Between $\mathrm{mm}$, the absolute value of $\mathrm{RB}$ is less than $20 \%$. Among them, the degree of improvement of DC-MSWEP in summer and autumn is more apparent. Compared with MSWEP, RB and RMSE reduced $(-12.59 \%$ and $-14.55 \% \longrightarrow-6.29 \%$ and $-7.27 \%$, respectively; $16.06 \mathrm{~mm}$ and $9.17 \mathrm{~mm} \longrightarrow 8.03 \mathrm{~mm}$ and $4.59 \mathrm{~mm}$, respectively), while CC increased (0.61 and $0.69 \longrightarrow 0.95$ and 0.96 ), respectively). DC-MSWEP performs the best in spring, which is significantly better than DC-GPM and DC-GSMAP, while DCGSMAP performs better in summer, autumn, and winter. In general, after the downscaling correction, the accuracy of GPM, SMAP, and MSWEP has greatly improved, especially that of DC-GSMAP. After downscaling correction has the lowest RMSE and lower RB, DC-GSMAP has better error performance.

Figure 7 shows the performance of all three classification statistical indicators of SPPs and DC-SPPSs in each season. Of the three SPPs, MSWEP has the highest POD in each season, MSWEP has the highest FAR in each season, GSMAP is the second, and GPM is the lowest. GSMAP has the highest ETS in spring, autumn, and winter, GPM is the second highest, and MSWEP is the lowest. It shows that when a precipitation event actually occurs, GSMAP has a higher frequency of successfully hitting a precipitation event, and a lower frequency of misrecognizing precipitation events, while MSWEP is the opposite, with a higher POD in each season and a higher FAR, which is consistent with the previous research conclusions. Similarly, it also reflects that MSWEP has difficulties in accurately detecting precipitation events. Compared with SPPs, DC-SPPs have a better ability to characterize precipitation events in all seasons. DC-GPM performs better than DC-GSMAP and DC-MSWEP in all seasons. It has a higher POD, the lowest FAR, and the 


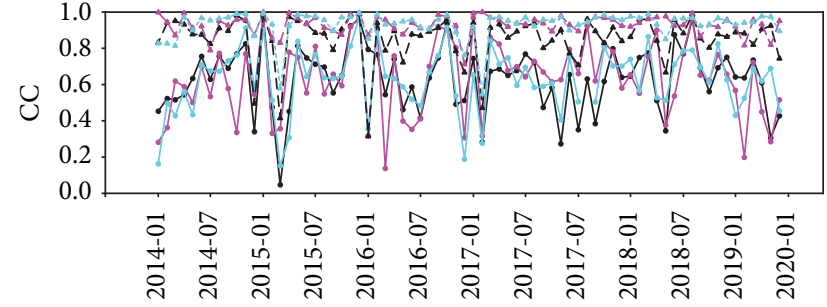

Time (year/month)

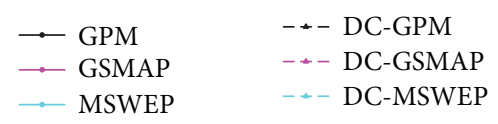

(a)

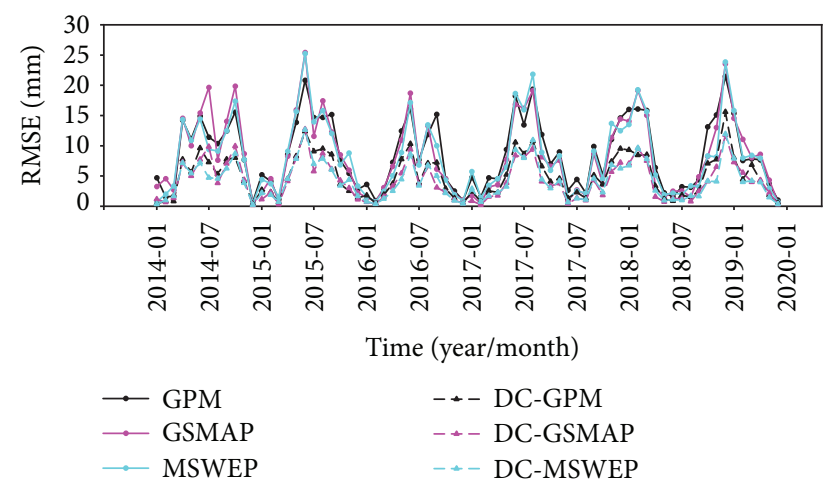

(c)

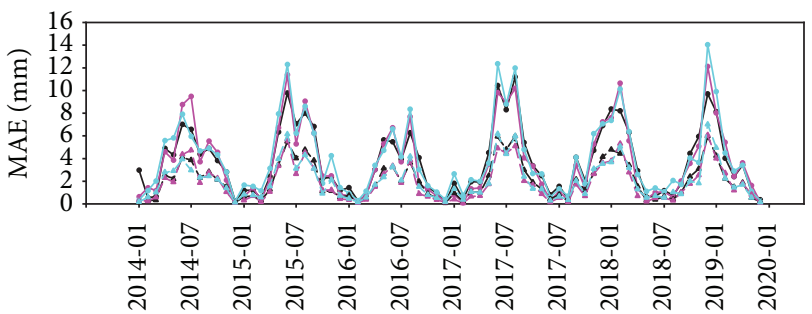

Time (year/month)

$$
\begin{array}{ll}
\because \text { GPM } & \cdots \text { DC-GPM } \\
\because \text { GSMAP } & \cdots \text { DC-GSMAP } \\
\because \text { MSWEP } & - \text { DC-MSWEP }
\end{array}
$$

(b)

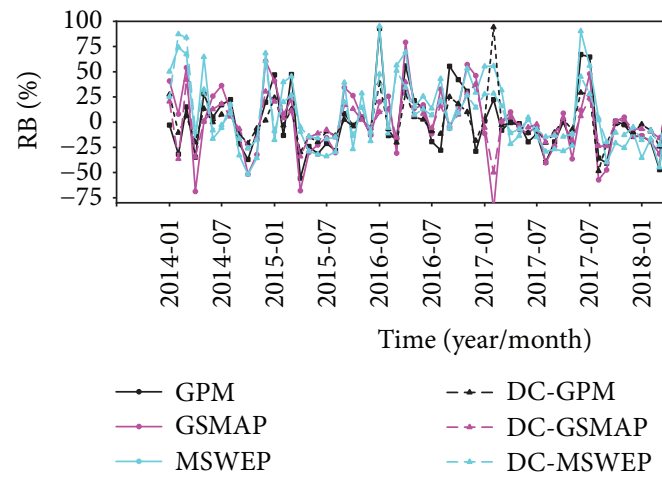

(d)

Figure 5: The monthly time series of error evaluation metrics for SPPs and DC-SPPs in the PTRB from January 2014 to December 2019. (a) CC, (b) MAE, (c) RMSE, and (d) RD.

highest ETS. In addition, except for MSWEP and DCMSWEP, all precipitation products have better precipitation detection capabilities during the rainy season.

\subsection{Spatial Differences of the Performance of SPPs and DC-SPPs}

4.2.1. Basin Scale. The spatial distribution of CC, MAE, RMSE, and $\mathrm{RB}$ can help researchers predict error propagation in hydrological applications. The spatial distribution of the continuous statistical indicators of SPPs and DC-SPPs in the PTRB is shown in Figures 8 and 9. The error evaluation indicators of GPM, GSMAP, and MSWEP have similar spatial distribution patterns. Of them, CC is higher in the southern and northeastern parts of the basin. The CC distribution of GPM is better in the entire basin, and the range of high CC values is significantly wider. Compared with GSMAP and MSWEP, RMSE and RB are obviously larger, which is consistent with this result of high correlation and high error. The MAE and RMSE of the three gradually increase from south to north, mainly because the northern part of the basin is highlands, and the southern part of the basin is highlands and lowlands. RB is greater than 0 in the southern part of the basin. The overestimation of GSMAP is the most serious, reaching the highest of $10.73 \%$, while in the northern part of the basin, it is less than 0 . The underestimation of GPM is highly significant, reaching the levels of $-25.12 \%$. As far as the spatial distribution of precipitation error in the basin is concerned, the accuracy of GSMAP error is better, which has a lot to do with the topography of the basin. The topography of the northern part of the basin are extremely complex, which brings high uncertainty errors to various precipitation measurement methods. Direct application to hydrological simulation has certain uncertainties. Therefore, downscaling correction is of great significance.

The three precipitation products of DC-GPM, DCGSMAP, and DC-MSWEP not only retain the error spatial distribution characteristics of SPPs but also greatly improve the spatial accuracy of errors and deviations. The three sets of DC-SPPs can basically reflect the spatial distribution characteristics of precipitation in the PTRB, and it is more reliable to describe the spatial error of precipitation. All CC are above 0.90, and the maximum range of MAE for DC-GPM, DC-GSMAP, and DCMSWEP is $1.61-1.99 \mathrm{~mm}, 1.48-5.80 \mathrm{~mm}$, and $1.84-2.17 \mathrm{~mm}$, respectively, and the maximum range of RMSE is $4.47-5.57 \mathrm{~mm}, 4.30-5.80 \mathrm{~mm}$, and $4.23-5.66 \mathrm{~mm}$, respectively. Almost all RBs are greater than 0 in the southern part of the basin. Among them, the overestimation of DC-GSMAP is the most serious, reaching $12.92 \%$, while in the northern part of the basin, almost all are less than 0 . The underestimation of DC-GPM is the most serious, reaching $-10.06 \%$. Although the correlation 


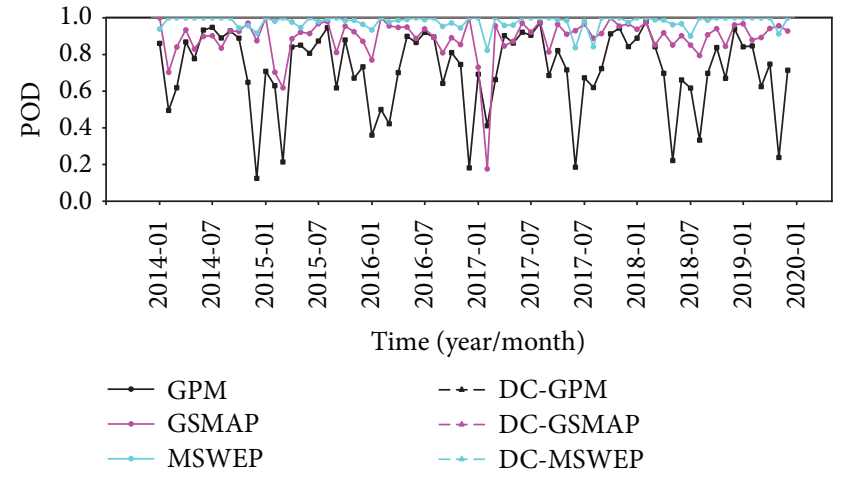

(a)

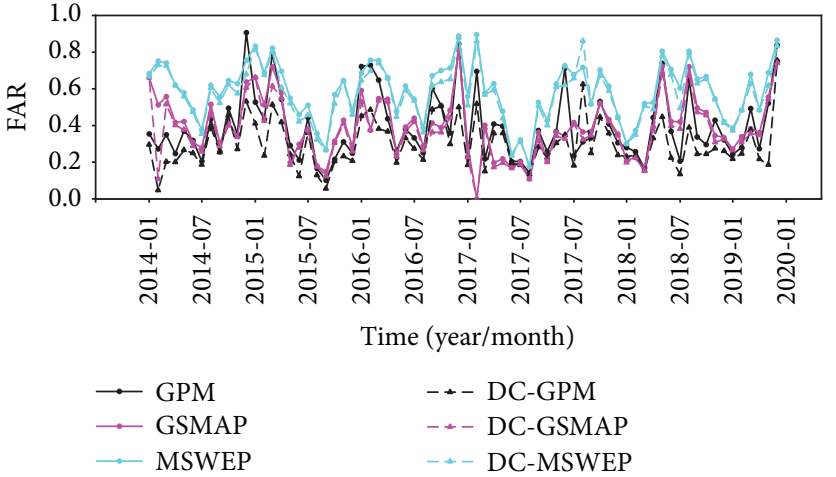

(b)

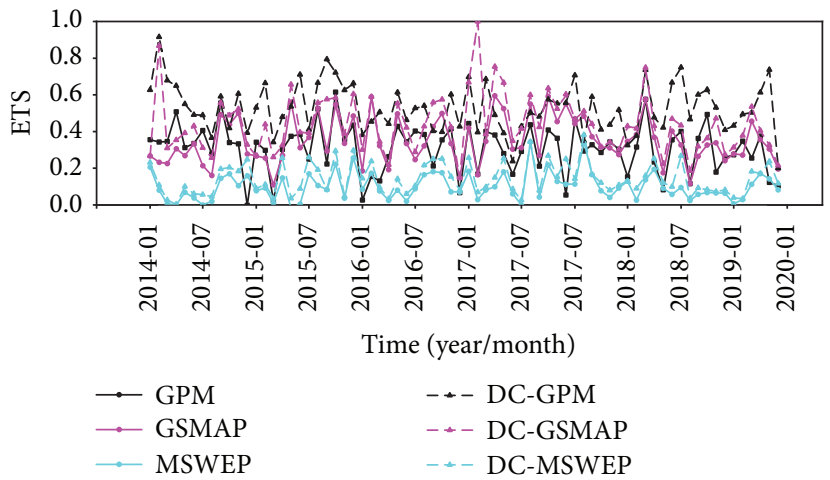

(c)

FIGURE 6: The monthly time series of classification evaluation metrics for SPPs and DC-SPPs in the PTRB from January 2014 to December 2019. (a) POD, (b) FAR, and (c) ETS.

TABLE 4: Comparison of error evaluation metrics between seasonal SPPs and DC-SPPs.

\begin{tabular}{|c|c|c|c|c|c|c|c|}
\hline Season & Index & GPM & GSMAP & MSWEP & DC-GPM & DC-GSMAP & DC-MSWEP \\
\hline \multirow{4}{*}{ Spring } & $\mathrm{CC}$ & 0.64 & 0.64 & 0.67 & 0.88 & 0.93 & 0.96 \\
\hline & MAE & 3.34 & 3.05 & 3.56 & 1.80 & 1.53 & 1.78 \\
\hline & RMSE & 9.46 & 8.75 & 8.47 & 5.32 & 4.38 & 4.24 \\
\hline & $\mathrm{RB}$ & $-4.57 \%$ & $-8.17 \%$ & $-0.80 \%$ & $-4.35 \%$ & $-4.09 \%$ & $-0.40 \%$ \\
\hline \multirow{4}{*}{ Summer } & $\mathrm{CC}$ & 0.69 & 0.60 & 0.61 & 0.89 & 0.92 & 0.95 \\
\hline & MAE & 7.42 & 8.08 & 8.36 & 4.22 & 4.04 & 4.18 \\
\hline & RMSE & 15.17 & 16.50 & 16.06 & 9.25 & 8.25 & 8.03 \\
\hline & $\mathrm{RB}$ & $-17.64 \%$ & $-10.74 \%$ & $-12.59 \%$ & $-9.46 \%$ & $-5.37 \%$ & $-6.29 \%$ \\
\hline \multirow{4}{*}{ Autumn } & CC & 0.66 & 0.67 & 0.69 & 0.90 & 0.94 & 0.96 \\
\hline & MAE & 3.19 & 2.85 & 3.19 & 1.74 & 1.42 & 1.60 \\
\hline & RMSE & 9.81 & 9.30 & 9.17 & 5.43 & 4.65 & 4.59 \\
\hline & $\mathrm{RB}$ & $-10.13 \%$ & $-10.06 \%$ & $-14.55 \%$ & $-6.35 \%$ & $-5.03 \%$ & $-7.27 \%$ \\
\hline \multirow{4}{*}{ Winter } & CC & 0.80 & 0.88 & 0.74 & 0.93 & 0.97 & 0.95 \\
\hline & MAE & 0.82 & 0.59 & 1.05 & 0.43 & 0.29 & 0.53 \\
\hline & RMSE & 2.91 & 1.94 & 2.61 & 1.52 & 0.97 & 1.31 \\
\hline & $\mathrm{RB}$ & $11.72 \%$ & $2.74 \%$ & $37.87 \%$ & $4.94 \%$ & $1.55 \%$ & $18.93 \%$ \\
\hline
\end{tabular}

between DC-GPM is better, the error performance of DCGSMAP is significantly better, and DC-MSWEP is inferior to the former two in both aspects.

4.2.2. Station Scale. Within the spatial scale of a single station and the grid, the error evaluation metrics on the daily scale of each station are calculated as shown in Table 5. The results show that before downscaling correction, GPM performs better than GSMAP and MSWEP at most basin stations. For high correlation, $75 \%$ of the sites with a CC of GPM greater than 0.70 accounted for $75 \%$, while the sites with a CC of GSMAP and MSWEP 


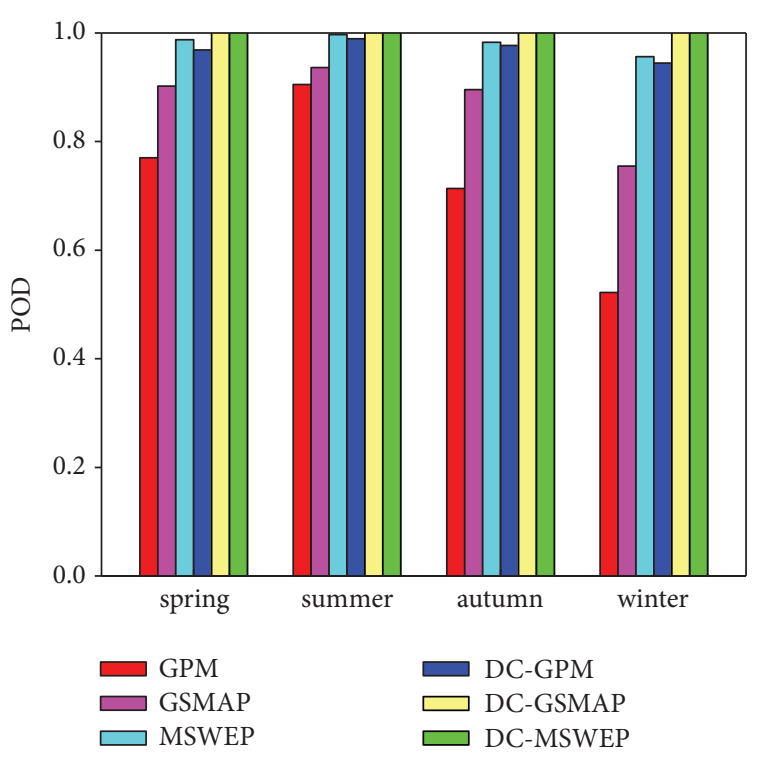

(a)

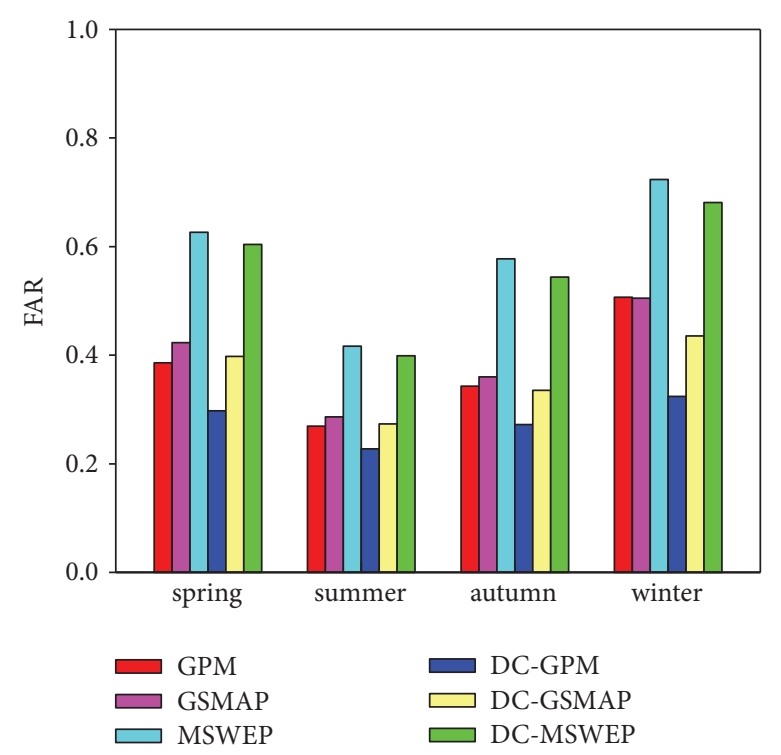

(b)

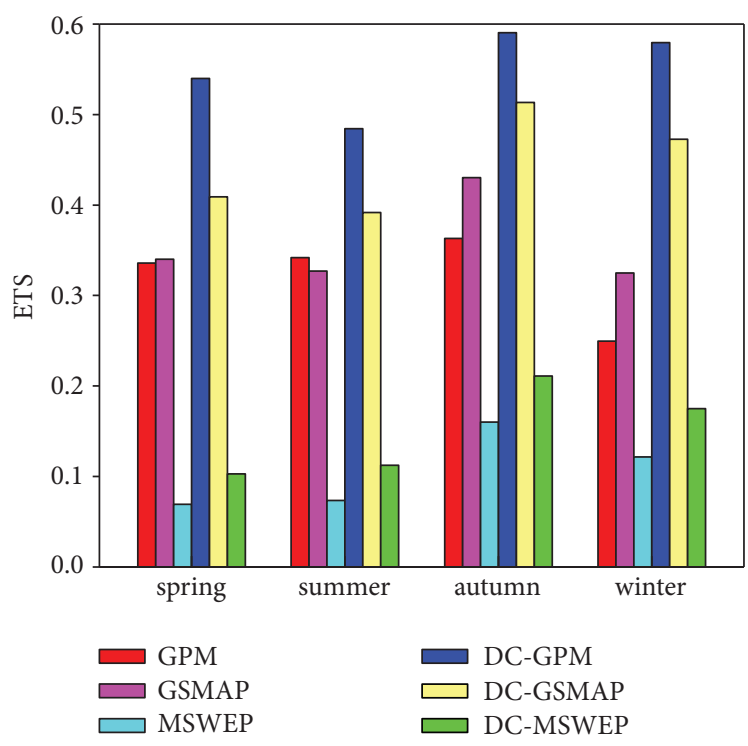

(c)

Figure 7: (a) POD, (b) FAR, and (c) ETS histograms of SPPs and DC-SPPs in each season.

greater than 0.70 accounted for only $12.5 \%$. In terms of MAE, the number of stations with GPM and GSMAP less than or equal to $4 \mathrm{~mm}$ accounted for $87.5 \%$ of the total number of stations, while MSWEP only had $37.5 \%$, which is similar to MAE in terms of RMSE. RB shows that the three underestimate the majority of the basin. However, the precipitation at the station in the southeastern region is significantly overestimated, especially the precipitation at the station in the southern region. The three types of DC-SPPs products have similar changes in the error assessment indicators at each site with the corresponding three SPPs precipitation products. The downscaling correction greatly improves the accuracy of each SPP and reduces the error.

Figure 10 shows the classified statistical index of all SPPs and DC-SPPs of each site. On the site scale, the POD of
MSWEP is significantly higher, followed by GSMAP and GPM. However, the FAR of MSWEP is also the highest, with 7 sites exceeding $0.5(87.5 \%)$, the credibility is low, which is the same as the previous research results. It is worth noting that the POD of GPM at all stations is smaller than that of GSMAP, but the FAR of GPM is lower than that of GSMAP. From the comprehensive ETS score, GSMAP performed better than GPM at the five sites (except XJ and HK), and the worst ETS performance was MSWEP (most sites were below 0.2 ). After downscaling, the three DC precipitation products' POD reached 1 , and the FAR decreased. From the comprehensive score ETS performance, the ETS of DC-GPM was higher than 0.6 at all stations, which was much higher than that of DC-GSAMP and DC-GSAMP. MSWEP performed the best. The changes before and after the downscaling of MSWEP were not very large, 


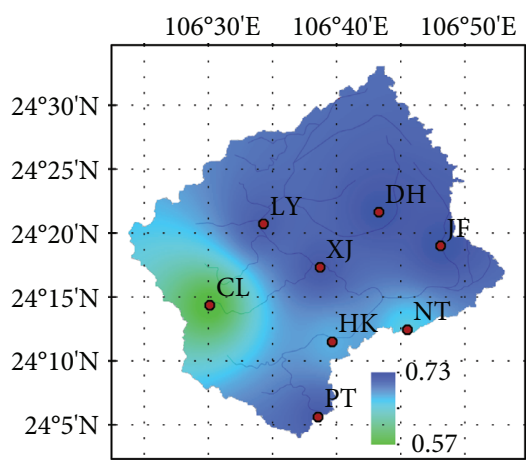

(a)

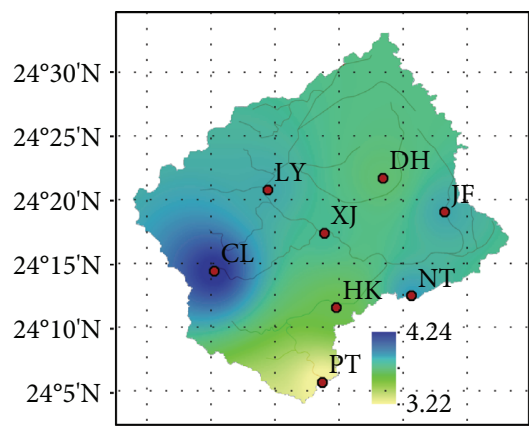

(d)

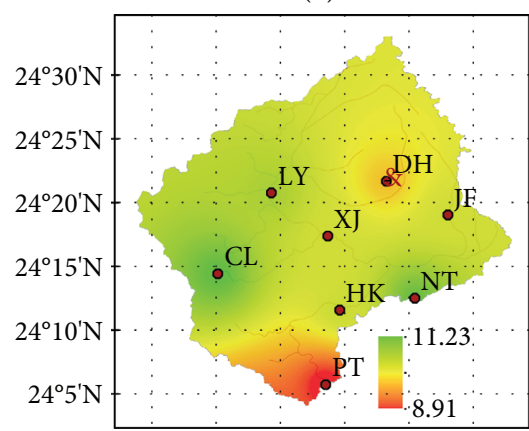

(g)

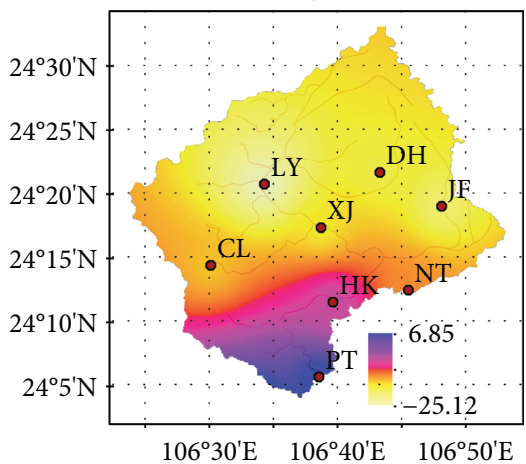

(j)

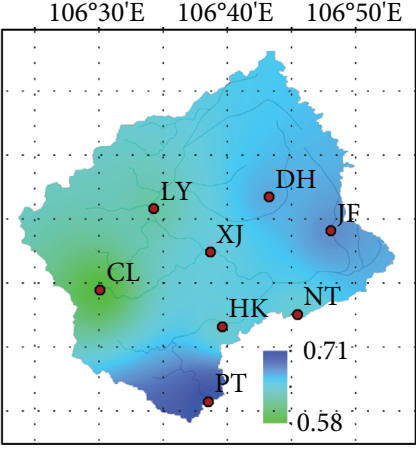

(b)

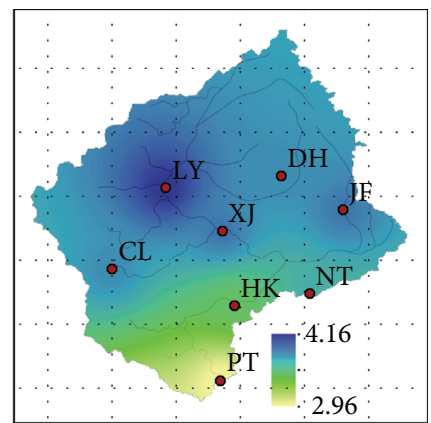

(e)

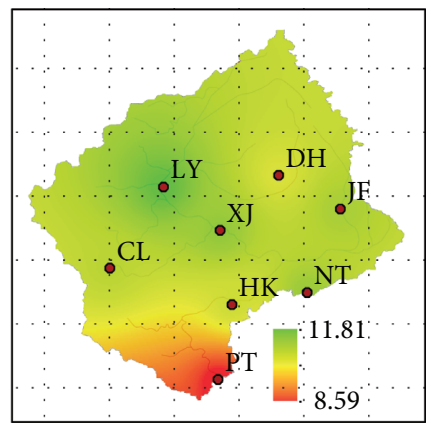

(h)

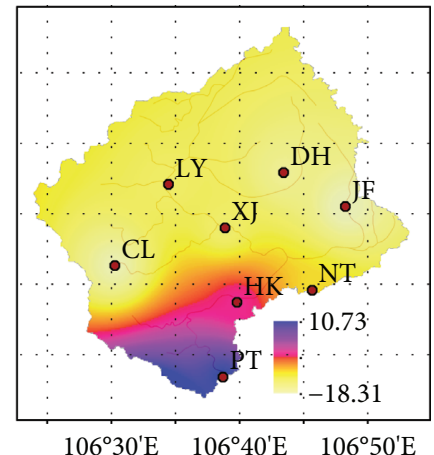

(k)

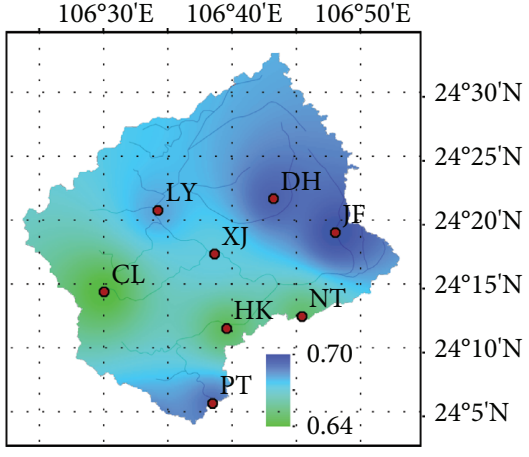

(c)

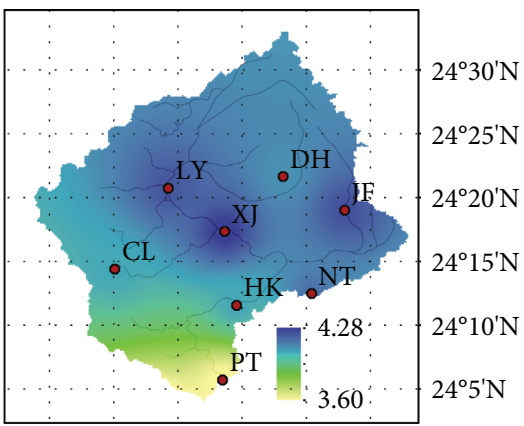

(f)

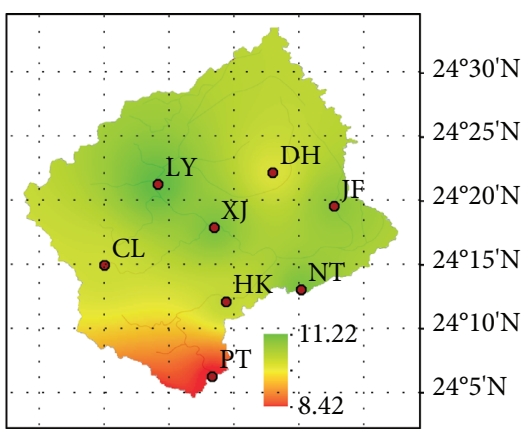

(i)

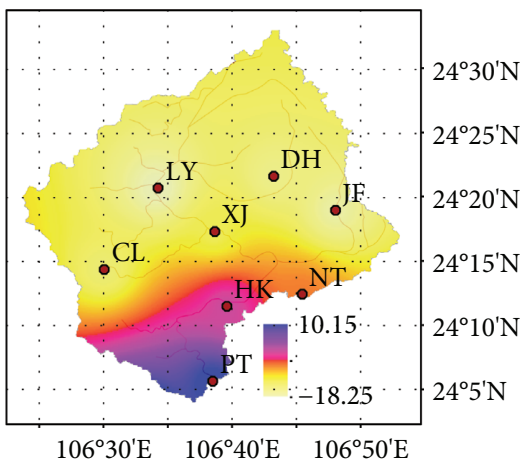

(l)

FIgURE 8: The spatial distribution of the three types of SPP error evaluation metrics in the PTRB: CC (a-c); MAE (d-f); RMSE (g-i); RB (j-l). (a) GPM CC, (b) GSMAP CC, (c) MSWEP CC, (d) GPM MAE, (e) GSMAP MAE, (f) MSWEP MAE, (g) GPM RMSE, (h) GSMAP RMSE, (i) MSWEP RMSE, (j) GPM RB, (k) GSMAP RB, and (l) MSWEP RB.

indicating that the downscaling process is not ideal and that its ability to capture precipitation events is insufficient. The application of precipitation event monitoring in the PTRB still needs to be cautious.
4.3. Probability Density Function of Precipitation Intensity. In many research applications, such as extreme weather monitoring, land-atmosphere interaction, and hydrometeorological research, the ability to detect precipitation with 


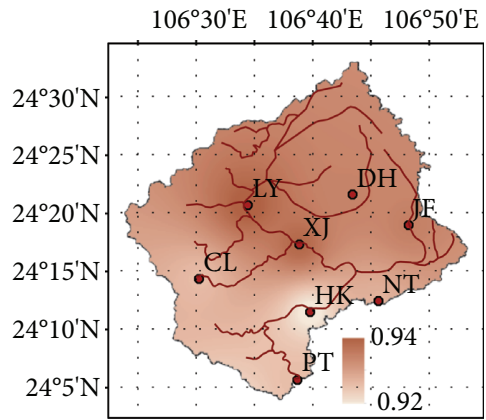

(a)

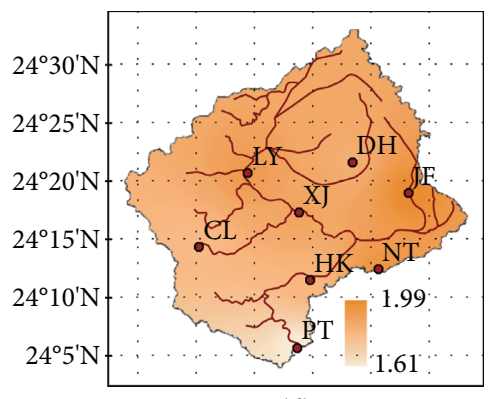

(d)

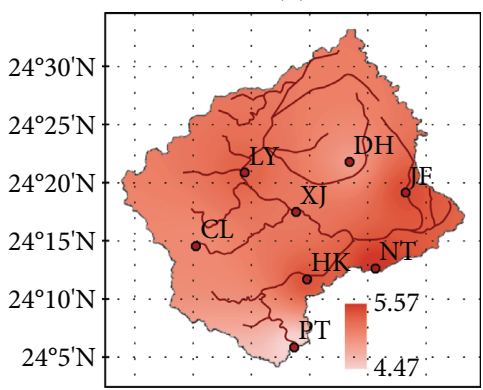

(g)

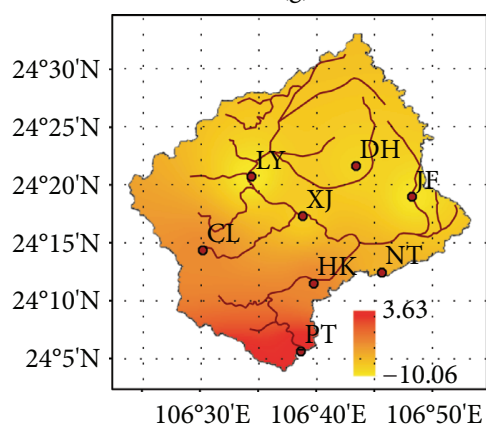

(j)

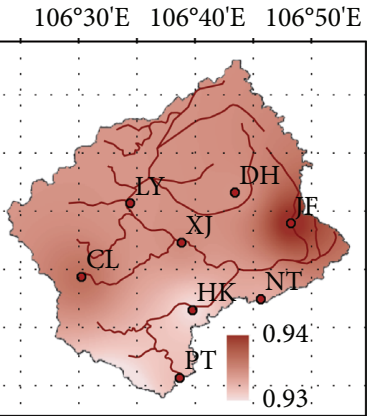

(b)

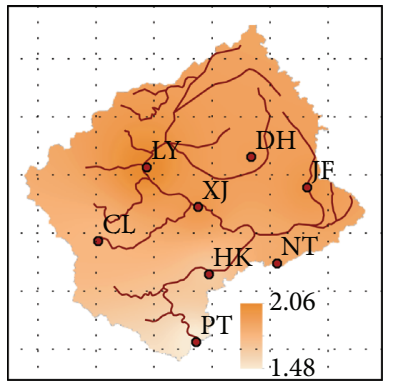

$(\mathrm{e})$

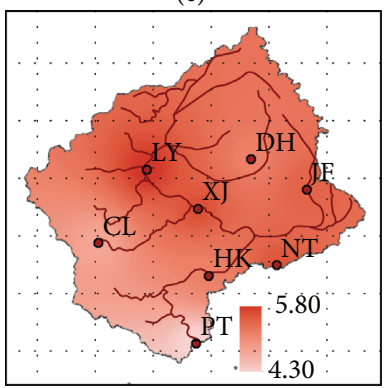

(h)

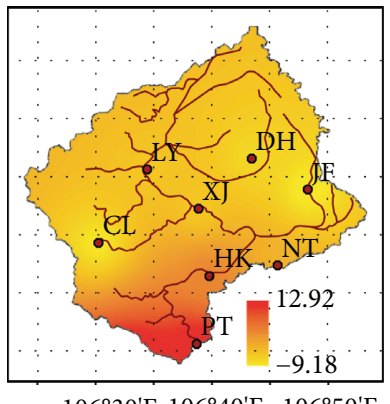

(k) $106^{\circ} 30^{\prime} \mathrm{E} \quad 106^{\circ} 40^{\prime} \mathrm{E} \quad 106^{\circ} 50^{\prime} \mathrm{E}$

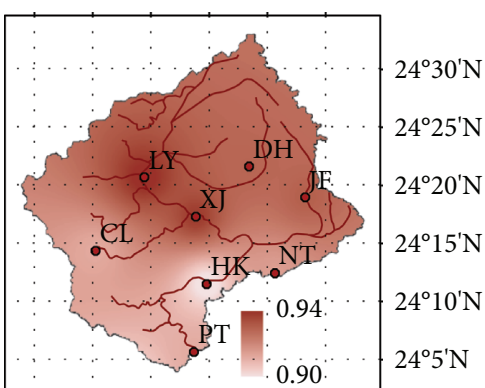

(c)

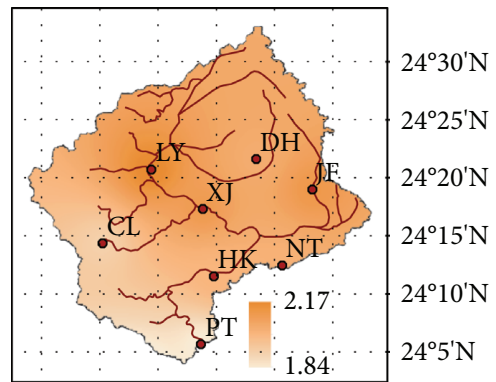

(f)

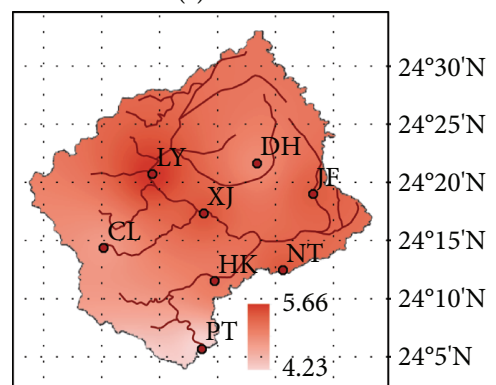

(i)

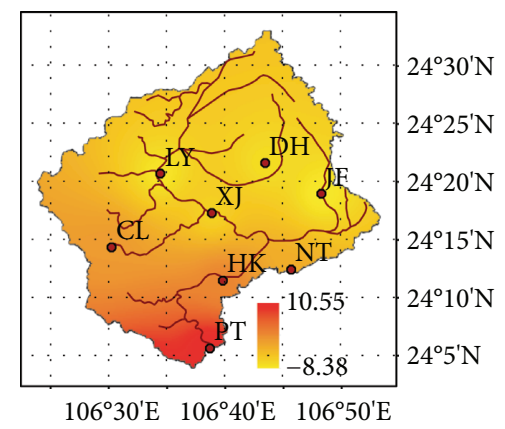

(1)

Figure 9: Spatial distribution of the three types of DC-SPPs error evaluation metrics in PTRB: CC (a-c); MAE (d-f); RMSE (g-i); RB (j-l). (a) DC-GPM CC, (b) DC-GSMAP CC, (c) DC-MSWEP CC, (d) DC-GPM MAE, (e) DC-GSMAP MAE, (f) DC-MSWEP MAE, (g) DCGPM RMSE, (h) DC-GSMAP RMSE, (i) DC-MSWEP RMSE, (j) DC-GPM RB, (k) DC-GSMAP RB, and (l) DC-MSWEP RB.

different precipitation intensities is as important as the average change of precipitation and temporal and spatial changes, and the same total precipitation can be attributable. Weak precipitation in a relatively strong time or heavy rainfall with a short duration will bring adverse effects on human production and life in many aspects. In this section, we will study the effects of all SPPs and DC-SPPs on the precipitation events of different intensities.
Figure 11 shows that as the precipitation threshold continues to increase, the accuracy of all SPPs and DC-SPPs for the representation of precipitation events, firstly, increases slightly and then decreases gradually. For the three SPPs, the precipitation event detection capability of MSWEP is significantly inferior to GPM and GSMAP at all precipitation thresholds, and the false alarm rate of precipitation events is higher. Especially when the precipitation intensity threshold is less than $10 \mathrm{~mm}$, 
TABLE 5: Error evaluation metrics of SPPs and DC-SPPs at each station.

\begin{tabular}{|c|c|c|c|c|c|c|c|}
\hline Stations & Index & GPM & GSMAP & MSWEP & DC-GPM & DC-GSMAP & DC-MSWEP \\
\hline \multirow{4}{*}{ LY } & $\mathrm{CC}$ & 0.71 & 0.62 & 0.68 & 0.94 & 0.93 & 0.96 \\
\hline & MAE & 3.85 & 4.16 & 4.21 & 1.92 & 2.06 & 2.17 \\
\hline & RMSE & 10.61 & 11.81 & 11.22 & 5.31 & 5.80 & 5.66 \\
\hline & $\mathrm{RB}$ & -25.12 & -12.99 & -18.25 & -10.06 & -6.15 & -8.03 \\
\hline \multirow{4}{*}{$\mathrm{DH}$} & $\mathrm{CC}$ & 0.72 & 0.66 & 0.69 & 0.93 & 0.93 & 0.96 \\
\hline & MAE & 3.68 & 3.82 & 4.08 & 1.84 & 1.91 & 2.04 \\
\hline & RMSE & 9.80 & 10.33 & 9.91 & 4.90 & 5.16 & 4.95 \\
\hline & $\mathrm{RB}$ & -17.23 & -15.80 & -14.85 & -8.62 & -7.93 & -7.42 \\
\hline \multirow{4}{*}{ JF } & $\mathrm{CC}$ & 0.73 & 0.67 & 0.70 & 0.93 & 0.94 & 0.96 \\
\hline & MAE & 3.85 & 3.90 & 4.22 & 2.00 & 1.95 & 2.11 \\
\hline & RMSE & 10.28 & 10.94 & 10.75 & 5.43 & 5.47 & 5.38 \\
\hline & $\mathrm{RB}$ & -18.98 & -18.32 & -16.77 & -9.74 & -9.18 & -8.38 \\
\hline \multirow{4}{*}{ CL } & $\mathrm{CC}$ & 0.57 & 0.58 & 0.64 & 0.92 & 0.94 & 0.95 \\
\hline & MAE & 4.24 & 3.83 & 4.04 & 1.79 & 1.77 & 1.92 \\
\hline & RMSE & 11.23 & 10.72 & 10.08 & 5.02 & 4.77 & 4.81 \\
\hline & $\mathrm{RB}$ & -14.33 & -17.65 & -13.41 & -3.21 & -0.96 & -2.03 \\
\hline \multirow{4}{*}{ XJ } & $\mathrm{CC}$ & 0.72 & 0.64 & 0.67 & 0.94 & 0.93 & 0.96 \\
\hline & MAE & 3.77 & 3.90 & 4.28 & 1.89 & 1.95 & 2.10 \\
\hline & RMSE & 10.28 & 11.24 & 10.93 & 5.14 & 5.62 & 5.43 \\
\hline & $\mathrm{RB}$ & -16.14 & -13.34 & -11.76 & -8.07 & -6.71 & -6.59 \\
\hline \multirow{4}{*}{ HK } & $\mathrm{CC}$ & 0.67 & 0.64 & 0.64 & 0.92 & 0.93 & 0.95 \\
\hline & MAE & 3.60 & 3.46 & 4.04 & 1.82 & 1.66 & 2.01 \\
\hline & RMSE & 10.34 & 10.50 & 10.21 & 5.39 & 5.18 & 5.12 \\
\hline & $\mathrm{RB}$ & -5.47 & -4.13 & -1.32 & -2.97 & -2.81 & -0.38 \\
\hline \multirow{4}{*}{ NT } & CC & 0.66 & 0.64 & 0.65 & 0.93 & 0.93 & 0.95 \\
\hline & MAE & 3.90 & 3.69 & 4.15 & 1.95 & 1.85 & 2.03 \\
\hline & RMSE & 11.14 & 11.12 & 10.97 & 5.57 & 5.57 & 5.40 \\
\hline & $\mathrm{RB}$ & -12.21 & -10.41 & -6.29 & -6.10 & -5.07 & -3.59 \\
\hline \multirow{4}{*}{$\mathrm{PT}$} & $\mathrm{CC}$ & 0.72 & 0.71 & 0.69 & 0.92 & 0.93 & 0.94 \\
\hline & MAE & 3.22 & 2.96 & 3.60 & 1.61 & 1.48 & 1.85 \\
\hline & RMSE & 8.91 & 8.59 & 8.42 & 4.46 & 4.29 & 4.23 \\
\hline & $\mathrm{RB}$ & 6.80 & 7.48 & 10.15 & 3.40 & 3.70 & 6.63 \\
\hline
\end{tabular}

the POD and FAR of MSWEP are higher than GPM and GSMAP, but ETS is the lowest. It may be related to the integration of MSWEP into multiple real-time satellite precipitation data sets, and the satellite detection signal mistakenly regarded some cloud gathering locations as precipitation events. This is also the main reason for the false alarm rate of all three SPPs. When the precipitation intensity threshold exceeds $10 \mathrm{~mm}$, the POD and ETS values of MSWEP are both small, indicating that MSWEP has very weak detection capabilities for moderate rain events and high-intensity precipitation events. As for GSMAP and GPM, when the precipitation threshold is less than $10 \mathrm{~mm}$, the change curve of GSMAP's POD and ETS values are above GPM, and the change curve of FAR is also lower than the FAR of GPM, reflecting the precipitation event detection capability of GSMAP within this threshold range better than GPM. It proves that GSMAP has a better ability to capture light rain and microprecipitation events. It may be related to the use of CPC daily precipitation analysis data in the inversion algorithm of GSMAP instead of the GPCP monthly data set. Within the threshold range of 10-20 mm, GPM and GSMAP have the same detection capabilities for moderate rain events, which may be related to the fact that the original satellite precipitation data of GPM and GSMAP come from the same satellite observation system. When the precipitation threshold is in the range of
$20 \mathrm{~mm}$ to $40 \mathrm{~mm}$, the detection performance of GPM precipitation events is slightly better than that of GSMAP. After the precipitation intensity threshold exceeds $40 \mathrm{~mm}$, the POD of the three SPPs is lower than 0.4, the FAR is higher than 0.4, and the comprehensive score ETS is lower than 0.3, which indicates that the detection capabilities of the three SPPs for high-intensity precipitation events need to be improved, especially for heavy rain and heavy rain events.

After downscaling correction, with the increase of the precipitation intensity threshold, the change trend of the precipitation event detection ability indicators of the three DC-SPPs is similar to that of SPPs. However, for the same precipitation product and its derived downscaling products, the POD and ETS under different precipitation intensity thresholds increased significantly, while the FAR decreased significantly, indicating that downscaling correction has improved the precipitation event detection ability of SPPs. The improvement of FAR of DC-GSMAP is very obvious, and ETS is better than DC-GPM and DC-GSMAPat most thresholds, indicating that the precipitation event detection ability of DC-GSMAP is better than DC-GPM and DCMSWEP under most thresholds, which has a certain degree of credibility in its ability to detect precipitation events in the PTRB. In general, the three SPPs have certain deficiencies in 

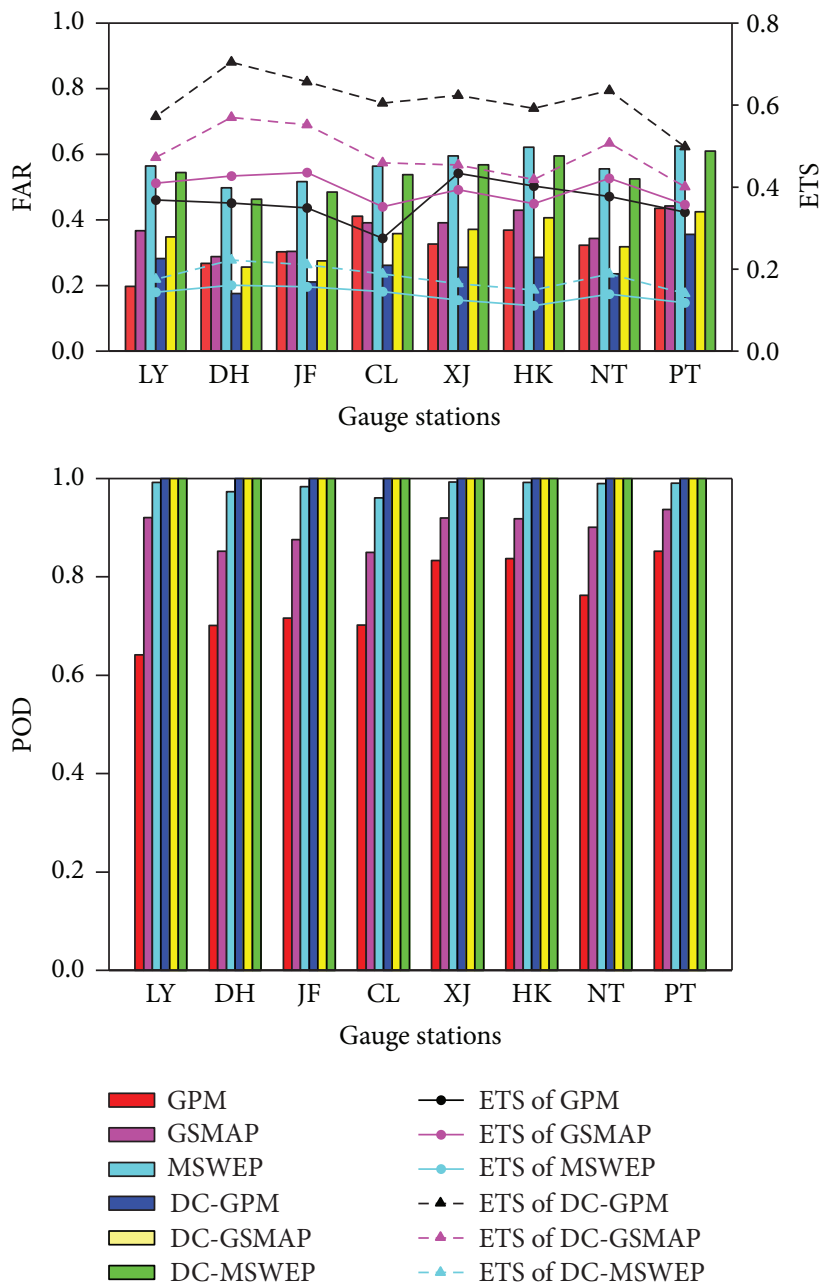

FIGURE 10: Histogram of classified statistical indicators of SPPs and DC-SPPs at each site.

detecting precipitation events and accurately estimating the precipitation levels. Ground observations can detect precipitation events more directly and accurately, downscaling and correcting satellite precipitation products by combining multisource remote sensing data and ground observation data $t$, which can enhance the ability of SPPs to detect precipitation events of different magnitudes. Overall, the method showed encouraging results for downscaling correction of the SPPS.

\subsection{Performance of SPPs at Hydrological Level}

4.4.1. Calibration and Validation of Streamflow. Figure 12 compares the daily hydrological curve observed at Pingtang Hydrological Station with the simulated hydrological curve using precipitation based on ground station measurements during calibration and verification. During the calibration period, the XAJ model using rain gauge precipitation achieved good results in daily runoff simulation. The NSE and lgNSE values are high, 0.88 and 0.80 , respectively, and the $\mathrm{RE}$ value is low at $-3.10 \%$. During the verification period, the hydrological performance decreased slightly, and the NSE and lgNSE decreased slightly to 0.86 and 0.64 , respectively, and the RE was $-0.40 \%$. However, the $\mathrm{XAJ}$ model usually underestimates the peak flow of the basin during the flood season. On the one hand, the reason is that the local sparse rain gauge network may not be able to fully capture the precipitation storm center to a large extent. On the other hand, it may be that the complicated confluence process of the karst basin is more complicated, which leads to a slight underestimation of the high flow of the basin. In general, the Grid-XAJ model has certain applicability in the PTRB and can be used to evaluate the applicability of SPPs and DC-SPPs in river basins.

4.4.2. Runoff Simulation Results-Using the SPPs. After the model is calibrated, the parameters of the Grid-XAJ model are calibrated using the controlled variable method and the rainfall station as the benchmark. GPM, GSMAP, and MSWEP are used as inputs to drive the model to simulate daily runoff during the validation period and evaluate the three SPPS hydrological utilities. Figure 13 shows that the simulated hydrological curve based on GPM is in good agreement with the observed runoff and peak flow. NSE and $\operatorname{lgNSE}$ are 0.64 and 0.54 , respectively, while RE is $-18.8 \%$, 


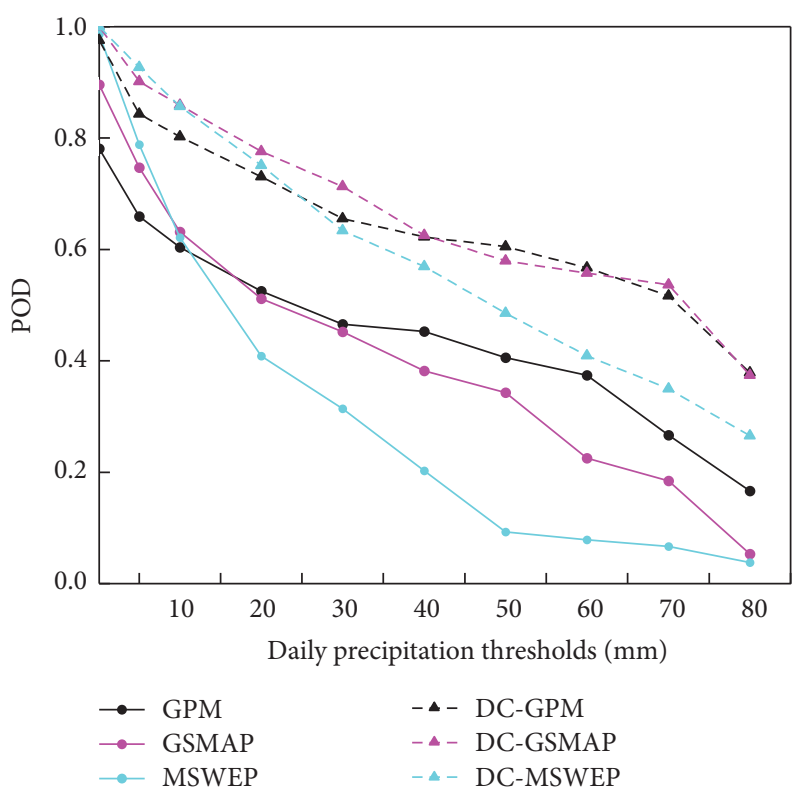

(a)

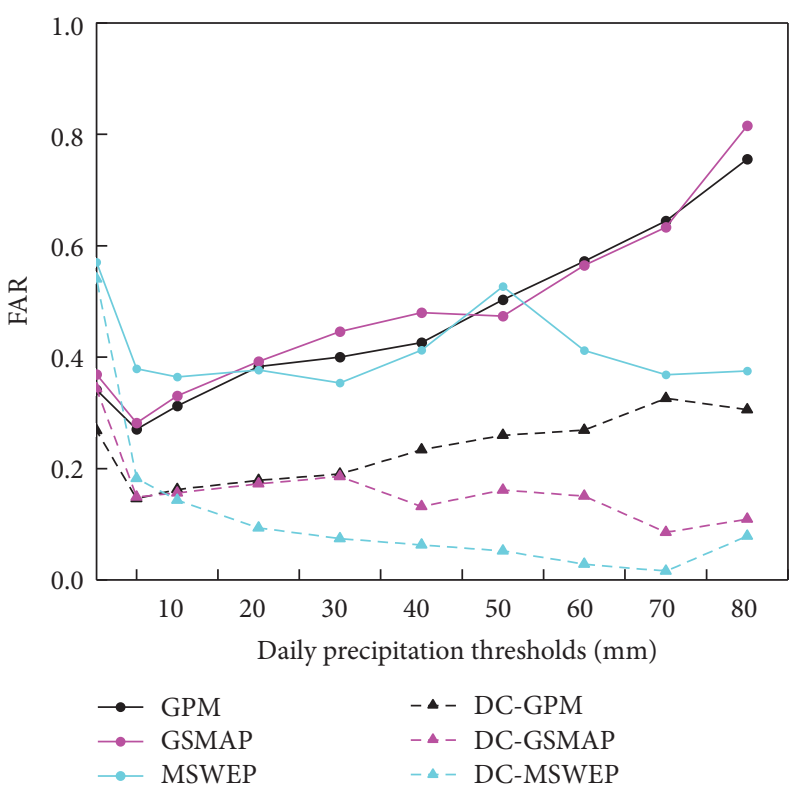

(b)

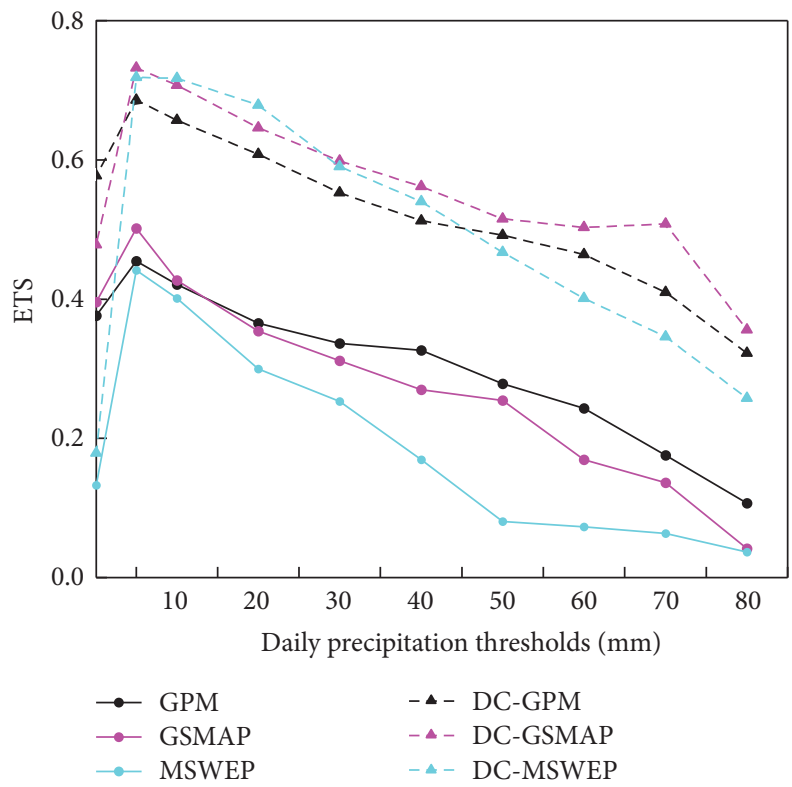

(c)

FIgUre 11: (a) POD, (b) FAR, and (c) ETS of SPPs and DC-SPPs under different precipitation thresholds.

which indicates that $18.8 \%$ of the total runoff in the basin is underestimated. The hydrological simulation effects of GSMAP and MSWEP are similar, with the NSE values of 0.50 and 0.52 and lgNSE values of 0.50 and 0.52 , respectively. All driven models capture the temporal changes in historical daily runoff in the basin, but the MSWEP RB is $-20.16 \%$, which underestimates that the total runoff is $-20.16 \%$, especially the most serious underestimation of the peak flow. The RE of GSMAP is $-12.9 \%$, and the error performance is the best. The three SPPs simulations show that the runoff performance is poor in capturing the peak value, and the total runoff is underestimated more seriously. This may be caused by the three SPPs underestimating the precipitation in the entire basin at the basin scale.
4.4.3. Runoff Simulation Results-Using the DC-SPPs. Using the same set of model parameters used to evaluate the hydrological utility of SPPs, DC-GPM, DC-GSMAP, and DC-MSWEP are used to simulate daily runoff during the validation period and evaluate the hydrological utility of DC-SPPs. Figure 14 shows that the hydrological curves simulated based on the three DC-SPPs-driven XAJ models are in good agreement with the observed runoff and peak flow. The NSE and lgNSE of DC-GPM are 0.78 and 0.58, respectively, and the RE is $-9.80 \%$. The NSE and lgNSE of DC-GSMAP are 0.75 and 0.56 , respectively, the RE is $-6.00 \%$, the NSE and lgNSE of DC-MSWEP are 0.76 and 0.57 , respectively, and the RE is $-8.40 \%$. The hydrological simulation characteristics of the three SPPs are similar. 


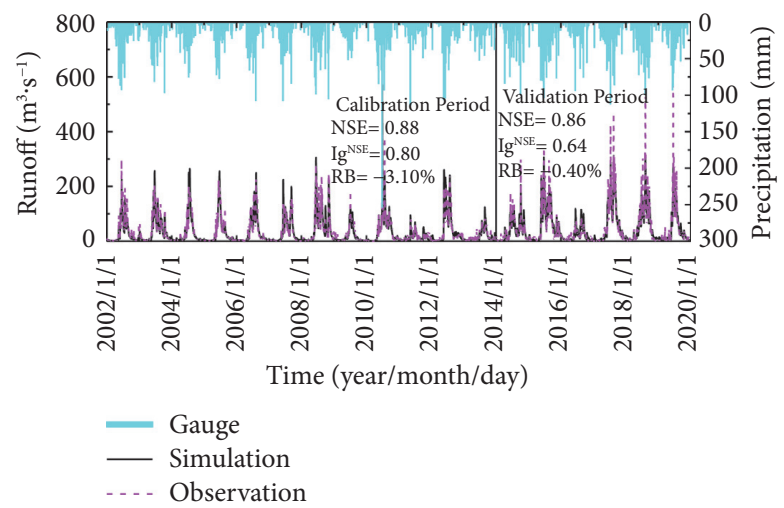

Figure 12: The hydrological curve of daily observations at Pingtang Hydrological Station and the simulation based on the measured precipitation during the calibration (January 1, 2002, to December 31, 2013) and verification (January 1, 2014, to December 31, 2019) hydrological curves are compared. Gauge represents the daily precipitation based on the gauge, observation represents the daily runoff observed by the hydrological station, and simulation is the daily runoff obtained from the precipitation simulation using the rain gauge station.

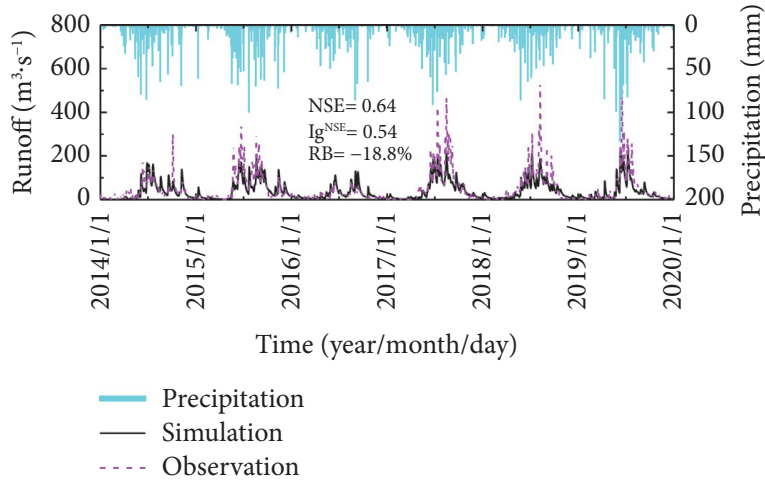

(a)

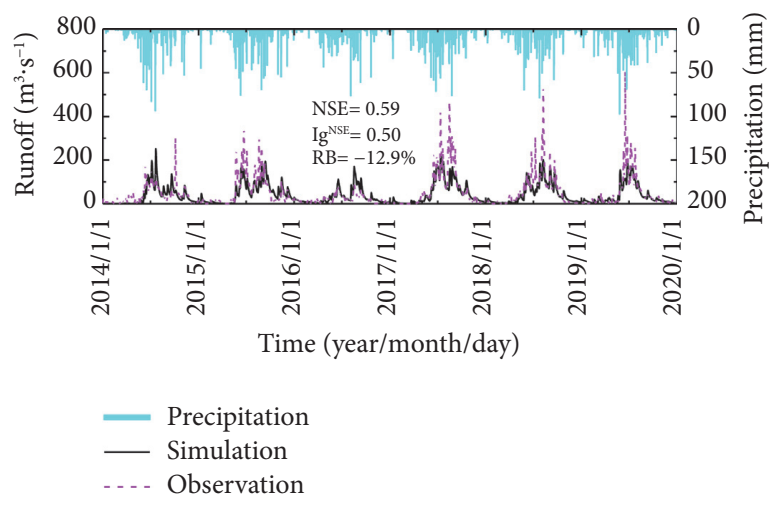

(b)

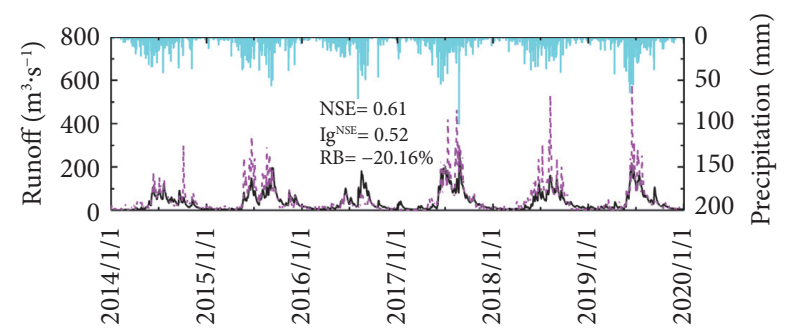

Time (year/month/day)

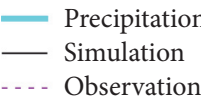

(c)

FIGURE 13: Simulation runoff verification process of three SPPs in PTRB: (a) GPM; (b) GSMAP; (c) MSWEP.

Compared with the three types of SPPs, they have different degrees of improvement. It is worth noting that the runoff simulated by the three types of DC-SPPs is lower than the observed value of the hydrological station, and the total water volume is less. In general, DC-GSMAP has the best hydrological utility, and it has better hydrological simulation characteristics in PTRB.

\section{Discussion}

The accuracy of different SPPs is very different, and the performance of different SPPs after downscaling is also very uncertain [2]. Most previous studies have only performed downscaling on a single satellite precipitation product and selected only one or two precipitation factors as 


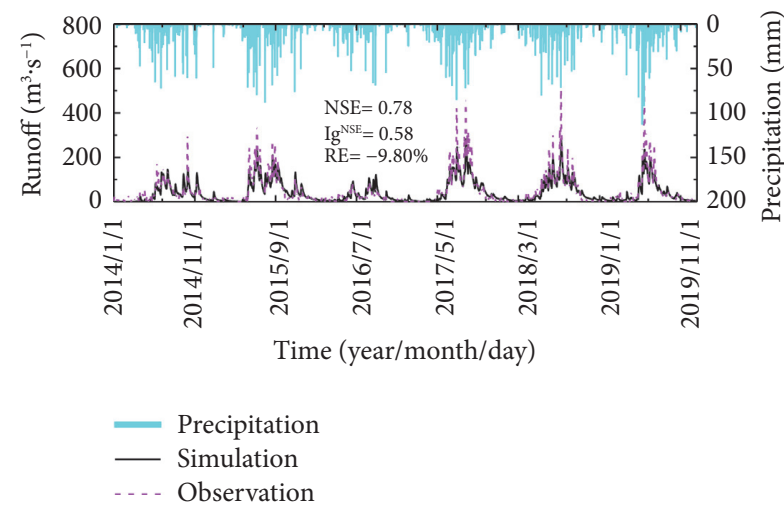

(a)

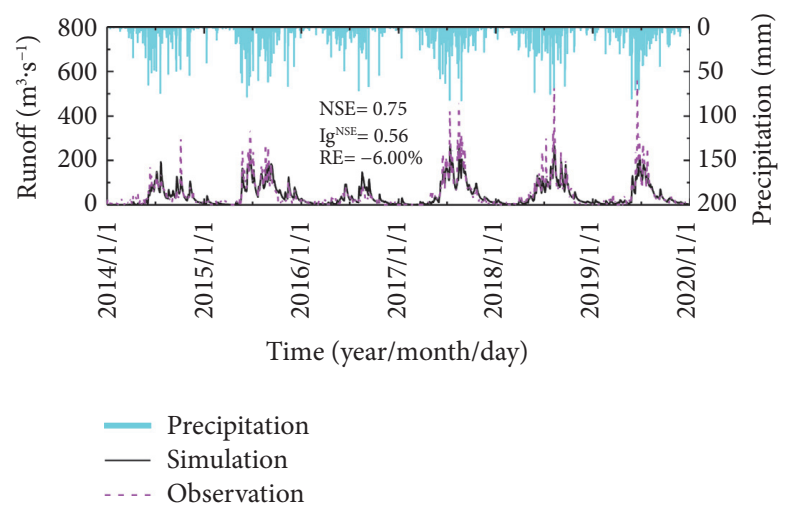

(b)

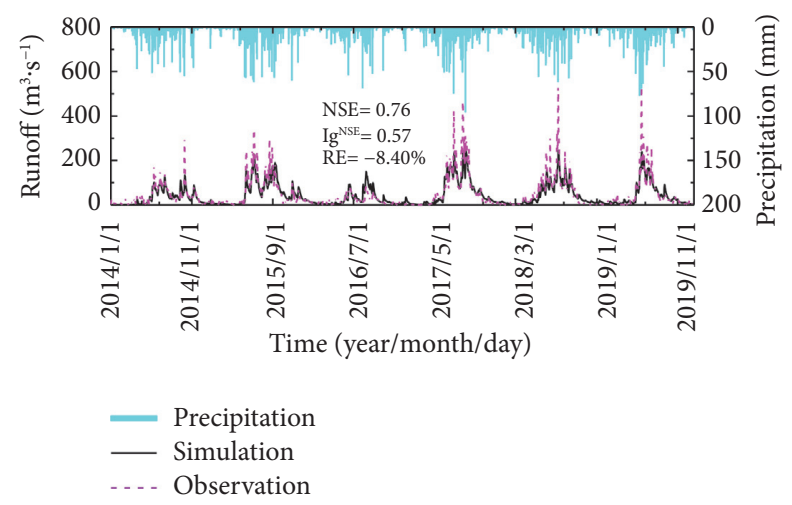

(c)

FIGURE 14: Simulation runoff verification process of three DC-SPPs in PTRB: (a) DC-GPM; (b) DC-GSMAP; (c) DC-MSWEP.

precipitation [25]. Compared with the explanatory variables, this study selected multiple precipitation impact factors (NDVI, aspect, slope, and elevation) and used three different high-resolution SPPs as benchmarks, downscaling through GWR and using GDA, combined with rainfall stations to make corrections and compare the results of the downscaling corrections of multiple different SPPs. It will help one select more accurate SPPs for downscaling corrections in the future to obtain better quality precipitation products, which is of great value to various hydrometeorological studies on small- and microscales [24, 53].

In most river basins with inaccurate measurements, hydrological modeling is a challenging problem [54]. The hydrological model requires a densely distributed gauge/station network to provide reasonable input for the model. In contrast, the actual stations are sparsely distributed and cannot capture the temporal and spatial changes in precipitation, and the use of sparse station data to evaluate SPPs has great uncertainty. In the small watersheds that some researchers pay more attention to, the measured data are very few or even nonexistent, which brings great difficulties to the assessment of SPPs. In addition, because of the limited data used in the calibration and verification process, hydrological modeling in catchment areas that lack measurement will face much uncertainty $[4,37]$. Therefore, some recent studies have focused on evaluating the performance of different precipitation datasets in hydrological simulations to simulate runoff in poor or unmeasured watersheds [13].
However, SPPs are usually stored in the form of grid-point precipitation. Understanding how to correct the grid-point precipitation data to obtain data with greater hydrological utility potential is important to establish a grid hydrological model and directly input satellite precipitation in the form of grid points. The current research aims to prove the potential benefits of the latest three SPPs and the corresponding DC-SPPs in hydrological applications, not the hydrological evaluation of a single satellite precipitation product and the Grid-XAJ distributed hydrological model selected in the article. The original resolution of the input satellite grid precipitation is retained, and the evaluation of SPPs is more straightforward. Most previous studies have evaluated the precipitation products of a single satellite and have obtained good-to-satisfactory performance in simulating water currents on daily and monthly time scales $[1,12,41,42]$. However, there is still a lack of research on downscaling correction and hydrological utility by comparing multiple satellite precipitation products. This study shows that different DC-SPPs combine the advantages of SPPs and rainfall stations, have a trend of reducing uncertainty, and have a high potential for hydrological applications. However, when different SPPs and different DC-SPPs are used as inputs to hydrological models, the hydrological utility results obtained by different precipitation products are not completely the same. Therefore, how to integrate different SPPs with each other in the future and learn from each other is still a major problem. In summary, the accuracy of the river simulation system depends to a large extent 
on the conditions of hydrological input. The results of this research can not only provide data support for the decisionmaking of the river basin management department but also provide important information for the research of river basin hydrology. Especially for some river basins lacking precipitation data or fewer precipitation data, but with similar hydrological conditions as this study, it is very important for the basin to formulate strategies to cope with climate change and mediumand long-term water resources planning.

Compared with SPPs, DC-SPPs can produce simulation results analogous to the measured values of rain gauges. It has certain reliability in long-term hydrological simulations with consistent data quality and has the potential to be used for water resource management and hydrological simulations in river basins with sparse or under measured data. However, this study did not consider the uncertainty of the hydrological model parameters and was limited to using the Grid-XAJ model to evaluate the hydrological simulation utility of three SPPs and three DC-SPPs. Therefore, in the future, a series of different hydrological models can be used to evaluate the hydrological effects of various SPPs and DC-SPPs at different watershed scales.

\section{Conclusion}

This article mainly discusses the time series error characteristics of three SPPs (GPM, GSMAP, and MSWEP) and three DC-SPPs (DC-GPM, DC-GSMAP, and DC-MSWEP) obtained by downscaling and correction using the GWR and GDA methods, as well as their temporal and spatial distributions and their abilities to characterize precipitation events. The error statistical indicators (CC, RB, MAE, and RMSE) and the classified statistical indicators (POD, FAR, and ETS) were used to compare the six precipitation products from January 1, 2014, to December 31, 2019, with the rainfall stations, with the error characteristics and effects of the six precipitation products being quantitatively analyzed. In addition, all SPPs and DC-SPPs were input into the Grid-XAJ model to simulate and observe the runoff of the river. NSE, lgNSE, and RB were used to compare the differences between the simulated runoff and the runoff observed by the hydrological station. The main results are as follows:

(1) All SPPs and DC-SPPs performed well from the perspective of three time scales: day, month, and quarter, with additional and clear results at the monthly scale. The use of GWR and GDA at the same time has a better downscaling correction effect, and the accuracies of the DC-SPPs are better than those of the SPPs. Compared with the observation results from the rainfall station, all precipitation products underestimate the precipitation in the PTRB, but the underestimation of DC-SPPs is not as severe as that of SPPs. DC-GPM has the best representation ability of precipitation events in all seasons, and its ETS score is much higher than that of other precipitation products. It is worth noting that the characterization capabilities of MSWEP and DC-MWEP in river basin precipitation events show high hit rates and high false alarm rates, and the overall effect is poor. Thus, they are not suitable for precipitation event monitoring in the watershed.

(2) The error performances of all SPPs and DC-SPPs have significant spatial variability, showing the characteristics of high correlation and high error distribution. Among them, MAE and RMSE have a similar pattern of spatial variation, with the basin being higher in the north and lower in the south. Overall, DC-GSMAP shows better performance than other precipitation products in most areas.

(3) With a continuously increasing threshold, the accurate capture ability of all SPPs and DC-SPPs for precipitation events, firstly, increases slightly, and then, it gradually decreases. There are major shortcomings in the ability to capture and monitor heavy rainfall events in the basin for the three SPPs. GSMAP performs better than GPM and MSWEP in monitoring light and small precipitation events in the basin, with MSWEP being the worst. Among the three types of DC-SPPs, DCGSMAP has a better overall performance in monitoring precipitation events with different precipitation intensities. Overall, the method showed encouraging results for improving and monitoring heavy rainfall events of the SPPs' daily precipitation.

(4) Three SPPs were used as input, and the Grid-XAJ model with a set driving rate was used to simulate the runoff. The NSEs of the three SPPs were all greater than 0.5 , and the NSE of GPM was up to 0.54, all of which captured the runoff of the watershed well. For the characteristics of the time change of flow, MSWEP underestimated the runoff of the river basin the most seriously and underestimated the runoff of the river basin by $-20.16 \%$. The hydrological effect was not good. The hydrological utility results of the three types of DC-SPPs show that the NSEs obtained by the three types of DC-SPPs are all higher than 0.75 , the obtained hydrological curve is in good agreement with the observed runoff and peak discharge, and the underestimation of the observed runoff has been improved. As GWR and GDA make the spatial distribution of precipitation more reasonable, the hydrological utility performance of each precipitation product is improved. From the perspective of comprehensive indicators, DC-GSMAP has higher NSE and lgNSE and the lowest RB. It also has the lowest RB in PTRB. A certain hydrological utility can be used to a certain extent as an input for the establishment of hydrological models in areas with a lack of data and no data.

\section{Data Availability}

Some or all rain gauge and flow data, models, or codes generated or used during the study are proprietary or confidential in nature and may only be provided with restrictions. The authors will conduct further research on this 
aspect in the future. The existing research data will be gradually developed in the subsequent papers, and it is only temporarily confidential at present.

\section{Conflicts of Interest}

The authors declare no conflicts of interest.

\section{Authors' Contributions}

G. S. conceived the original design of this paper and performed data curation, Y. W. carried out preliminary manuscript writing and improved the structure of the paper, G. W., R. S., and H. C. contributed to review and editing, and M. C. took part in the final review and funding. All authors have read and agreed to the published version of the manuscript.

\section{Acknowledgments}

This research was funded by the National Natural Science Foundation of China, under grant no. 51969004; the Guangxi Natural Science Foundation of China, under grant no. 2017GXNSFAA198361; and the Innovation Project of Guangxi Graduate Education, under grant no. YCBZ2019022.

\section{References}

[1] M.-H. Le, V. Lakshmi, J. Bolten, and D. D. Bui, "Adequacy of satellite-derived precipitation estimate for hydrological modeling in Vietnam basins," Journal of Hydrology, vol. 586, Article ID 124820, 2020.

[2] G. Tang, M. P. Clark, S. M. Papalexiou, Z. Ma, and Y. Hong, "Have satellite precipitation products improved over last two decades? A comprehensive comparison of GPM IMERG with nine satellite and reanalysis datasets," Remote Sensing of Environment, vol. 240, Article ID 111697, 2020.

[3] M. N. Anjum, I. Ahmad, Y. Ding et al., "Assessment of IMERG-V06 precipitation product over different hydro-climatic regimes in the Tianshan Mountains, north-western China," Remote Sensing, vol. 11, no. 19, p. 2314, 2019.

[4] Y. Derin, E. Anagnostou, A. Berne et al., "Evaluation of GPMera global satellite precipitation products over multiple complex Terrain regions," Remote Sensing, vol. 11, no. 24, p. $2936,2019$.

[5] C. Li, G. Tang, and Y. Hong, "Cross-evaluation of groundbased, multi-satellite and reanalysis precipitation products: applicability of the Triple Collocation method across Mainland China," Journal of Hydrology, vol. 562, Article ID S0022169418302920, 2018.

[6] G. J. Huffman, D. T. Bolvin, E. J. Nelkin et al., "The TRMM multisatellite precipitation analysis (TMPA): quasi-global, multiyear, combined-sensor precipitation estimates AAt fine scales," Satellite Rainfall Applications for Surface Hydrology, vol. 8, 2010.

[7] R. J. Joyce, J. E. Janowiak, P. A. Arkin, and P. Xie, "CMORPH: A method that produces global precipitation estimates from passive microwave and infrared data at high spatial and temporal resolution," Journal of Hydrometeorology, vol. 5, pp. 287-296, 2004.

[8] S. Sorooshian, K. L. Hsu, X. Gao, H. V. Gupta, B. Imam, and B. Dan, "Evaluation of PERSIANN system satellite-based estimates of tropical rainfall," Bulletin of the American Meteorological Society, vol. 81, pp. 2035-2046, 2000.

[9] H. Kou-Lin and G. Xiaogang, "Precipitation estimation from remotely sensed information using artificial neural networks," Journal of Applied Meteorology, vol. 39, 1997.

[10] G. Huffman, D. Bolvin, D. Braithwaite et al., "First results from the integrated multi-satellite retrievals for GPM (IMERG)," in Proceedings of the Egu General Assembly Conference, Vienna, Austria, April 2015.

[11] U. Tomoo, S. Kazushi, K. Takuji et al., "A Kalman filter approach to the global satellite mapping of precipitation (GSMaP) from combined passive microwave and infrared radiometric data (2. Global satellite mapping of precipitation (GSMaP) Project, Precipitation measurements from space)," Journal of the Meteorological Society of Japan. Series II, vol. 87, 2009.

[12] H. E. Beck, N. Vergopolan, M. Pan et al., "Global-scale evaluation of 22 precipitation datasets using gauge observations and hydrological modeling," Hydrology and Earth System Sciences, vol. 21, no. 12, pp. 6201-6217, 2017.

[13] L. Jiang and P. Bauer-Gottwein, "How do GPM IMERG precipitation estimates perform as hydrological model forcing? Evaluation for 300 catchments across Mainland China," Journal of Hydrology, vol. 572, 2019.

[14] S. Jiang, L. Ren, H. Yang et al., "Comprehensive evaluation of multi-satellite precipitation products with a dense rain gauge network and optimally merging their simulated hydrological flows using the Bayesian model averaging method," Journal of Hydrology, vol. 452-453, pp. 213-225, 2012.

[15] R. Khatakho, R. Talchabhadel, and B. R. Thapa, "Evaluation of different precipitation inputs on streamflow simulation in Himalayan River Basin,” Journal of Hydrology, vol. 599, 2021.

[16] S. Jianga, L. Rena, C. Y. Xub, B. Yonga, and Y. Fei, "Statistical and hydrological evaluation of the latest integrated multisatellite retrievals for GPM (IMERG) over a midlatitude humid basin in South China," Atmospheric Research, vol. 214, 2008.

[17] W. R. Huang, Y. H. Chang, and P. Y. Liu, "Assessment of IMERG precipitation over Taiwan at multiple timescalesScienceDirect," Atmospheric Research, vol. 214, pp. 239-249, 2018.

[18] J. Su, H. Lü, Y. Zhu, X. Wang, and G. Wei, "Component analysis of errors in four GPM-based precipitation estimations over mainland China," Remote Sensing, vol. 10, 2018.

[19] H. Guo, S. Chen, A. Bao, J. Hu, B. Yang, and P. Stepanian, "Comprehensive evaluation of high-resolution satellite-based precipitation products over China," Atmosphere, vol. 7, no. 1, p. 6, 2015.

[20] X. Li, Q. Zhang, and C.-Y. Xu, "Assessing the performance of satellite-based precipitation products and its dependence on topography over Poyang Lake basin," Theoretical and Applied Climatology, vol. 115, no. 3-4, pp. 713-729, 2014.

[21] A. A. Moreira, A. L. Ruhoff, D. R. Roberti, V. d. A. Souza, H. R. da Rocha, and R. C. D. d. Paiva, "Assessment of terrestrial water balance using remote sensing data in South America," Journal of Hydrology, vol. 575, pp. 131-147, 2019.

[22] X. Lu, G. Tang, X. Wang et al., "Correcting GPM IMERG precipitation data over the Tianshan Mountains in China," Journal of Hydrology, vol. 575, pp. 1239-1252, 2019.

[23] K. Venkatesh, K. Srinivas, and K. Preethi, "Evaluation and integration of reanalysis rainfall products under contrasting climatic conditions in India," Atmospheric Research, vol. 246, Article ID 105121, 2020. 
[24] X. Yan, H. Chen, B. Tian, S. Sheng, J. Wang, and J.-S. Kim, “A downscaling-merging scheme for improving daily spatial precipitation estimates based on random forest and cokriging," Remote Sensing, vol. 13, no. 11, p. 2040, 2021.

[25] F. Chen, Y. Gao, Y. Wang, F. Qin, and X. Li, "Downscaling satellite-derived daily precipitation products with an integrated framework," International Journal of Climatology, vol. 39, 2018.

[26] S. Xu, C. Wu, L. Wang, A. Gonsamo, Y. Shen, and Z. Niu, "A new satellite-based monthly precipitation downscaling algorithm with non-stationary relationship between precipitation and land surface characteristics," Remote Sensing of Environment, vol. 162, pp. 119-140, 2015.

[27] B. Fca, D. Ygc, C. Yw, and L. E. Xi, "A downscaling-merging method for high-resolution daily precipitation estimationScienceDirect," Journal of Hydrology, vol. 581, 2020.

[28] W. W. Immerzeel, M. M. Rutten, and P. Droogers, "Spatial downscaling of TRMM precipitation using vegetative response on the Iberian Peninsula," Remote Sensing of Environment, vol. 113, no. 2, pp. 362-370, 2009.

[29] Y. Cheng, Z. Li, Z. Yu, and Z. Ke, "A priori parameter estimates for a distributed, grid-based Xinanjiang model using geographically based information," Journal of Hydrology, vol. 468-469, pp. 47-62, 2012.

[30] Z. Chesheng, H. Jian, H. Shi, L. Liangmeizi, and D. Yuxuan, "Spatial downscaling of GPM annual and monthly precipitation using regression-based algorithms in a mountainous area," Advances in Meteorology, vol. 2018, Article ID 1506017, 13 pages, 2018.

[31] L. L. Patricia, W. W. Immerzeel, S. Rodríguez, S. Geert, and S. Jaap, "Spatial downscaling of satellite-based precipitation and its impact on discharge simulations in the Magdalena River basin in Colombia," Frontiers in Earth Science, vol. 6, p. $68,2018$.

[32] F. Jian, J. Du, X. Wei, P. Shi, L. Man, and X. Ming, "Spatial downscaling of TRMM precipitation data based on the orographical effect and meteorological conditions in a mountainous area," Advances in Water Resources, vol. 61, pp. 42-50, 2013.

[33] F. Chen, Y. Liu, Q. Liu, and X. Li, "Spatial downscaling of TRMM 3B43 precipitation considering spatial heterogeneity," International Journal of Remote Sensing, vol. 35, no. 9, pp. 3074-3093, 2014.

[34] Y. Chen, J. Huang, S. Sheng et al., "A new downscaling-integration framework for high-resolution monthly precipitation estimates: combining rain gauge observations, satellitederived precipitation data and geographical ancillary data," Remote Sensing of Environment, vol. 214, pp. 154-172, 2018.

[35] A. K. Ghorbanpour, T. Hessels, S. Moghim, and A. Afshar, "Comparison and assessment of spatial downscaling methods for enhancing the accuracy of satellite-based precipitation over Lake Urmia Basin," Journal of Hydrology, vol. 596, Article ID 126055, 2021.

[36] N. Zhao, "An efficient downscaling scheme for high-resolution precipitation estimates over a high mountainous watershed," Remote Sensing, vol. 13, no. 2, p. 234, 2021.

[37] C. Chen, Q. Chen, B. Qin, S. Zhao, and Z. Duan, "Comparison of different methods for spatial downscaling of GPM IMERG V06B satellite precipitation product over a typical arid to semi-arid area," Frontiers in Earth Science, vol. 8, pp. 1-16, 2020 .
[38] Z. Duan and W. G. M. Bastiaanssen, "First results from Version 7 TRMM 3B43 precipitation product in combination with a new downscaling-calibration procedure," Remote Sensing of Environment, vol. 131, pp. 1-13, 2013.

[39] M. J. M. Cheema and W. G. M. Bastiaanssen, "Local calibration of remotely sensed rainfall from the TRMM satellite for different periods and spatial scales in the Indus Basin," International Journal of Remote Sensing, vol. 33, no. 8, pp. 2603-2627, 2012.

[40] Y. Wehbe, M. Temimi, and R. F. Adler, "Enhancing precipitation estimates through the fusion of weather radar, satellite retrievals, and surface parameters," Remote Sensing, vol. 12, no. 8, p. 1342, 2020.

[41] N. Li, G. Tang, P. Zhao, Y. Hong, Y. Gou, and K. Yang, "Statistical assessment and hydrological utility of the latest multi-satellite precipitation analysis IMERG in Ganjiang River basin," Atmospheric Research, vol. 183, pp. 212-223, 2017.

[42] X. Li, Y. Chen, X. Deng, Y. Zhang, and L. Chen, "Evaluation and hydrological utility of the GPM IMERG precipitation products over the Xinfengjiang River Reservoir basin, China," Remote Sensing, vol. 13, no. 5, p. 866, 2021.

[43] C. Mo, M. Zhang, Y. Ruan et al., "Accuracy analysis of IMERG satellite rainfall data and its application in long-term runoff simulation," Water, vol. 12, no. 8, p. 2177, 2020.

[44] S. Khan, V. Maggioni, and P. E. Kirstetter, "Investigating the potential of using satellite-based precipitation radars as reference for evaluating multisatellite merged products," Journal of Geophysical Research: Atmospheres, vol. 123, 2018.

[45] G. Huffman, D. Bolvin, E. Nelkin, and C. Kidd, "Improving user access to the integrated multi-satellite retrievals for GPM (IMERG) products," in Proceedings of the Egu General Assembly Conference, Vienna Austria, April 2016.

[46] H. Beck, A. I. J. M. Van Dijk, V. Levizzani, and J. Schellekens, "MSWEP: 3-hourly 0.25 degrees global gridded precipitation (1979-2015) by merging gauge, satellite, and reanalysis data," Hydrology \& Earth System Sciences, vol. 21, 2017.

[47] N. W. Park, "Spatial downscaling of TRMM precipitation using geostatistics and fine scale environmental variables," Advances in Meteorology, vol. 2013, Article ID 237126, 9 pages, 2013.

[48] S. Shengjin Xie, Y. Liu, and F. Yao, "Spatial downscaling of TRMM precipitation using an optimal regression model with NDVI in inner Mongolia, China," Water Resources, vol. 47, no. 6, pp. 1054-1064, 2020.

[49] H. J. Bao, L. L. Wang, and Z. J. Li, "Hydrological daily rainfallrunoff simulation with BTOPMC model and comparison with Xin'anjiang model," Water Science and Water Engineering, vol. 3, no. 2, pp. 121-131, 2010.

[50] L. Ren, A. Ru, H. Jiang, F. Yuan, and M. Wang, "Application of remote sensing information about land use-land cover in flood forecasting with the Xin'anjiang model," Canadian Journal of Remote Sensing, vol. 30, 2014.

[51] Y. Zhao, W. Liao, and X. Lei, "Hydrological simulation for karst mountain areas: a case study of central Guizhou province," Water, vol. 11, no. 5, p. 991, 2019.

[52] C. Yao, J. Ye, Z. He, S. Bastola, K. Zhang, and Z. Li, "Evaluation of flood prediction capability of the distributed GridXinanjiang model driven by weather research and forecasting precipitation," Journal of Flood Risk Management, vol. 12, 2019. 
[53] Y. Fei, W. Bing, C. Shi et al., "Evaluation of hydrological utility of IMERG Final run V05 and TMPA 3B42V7 satellite precipitation products in the Yellow River source region, China," Journal of Hydrology, vol. 567, pp. 696-711, 2018.

[54] H. Li, Y. Zhang, F. H. S. Chiew, and S. Xu, "Predicting runoff in ungauged catchments by using Xinanjiang model with MODIS leaf area index," Journal of Hydrology, vol. 370, no. 1-4, pp. 155-162, 2009. 